\title{
Microstructural Characteristics and Mechanical Properties of Nanostructured and Conventional TiAlN and AlCrN Coatings on ASTM-SA210 Grade A-1 Boiler Steel
}

\author{
Vikas Chawla \\ D.A.V. College of Engineering and Technology, Kanina 123027, India \\ Correspondence should be addressed to Vikas Chawla; vikkydmt@gmail.com
}

Received 12 June 2013; Accepted 4 July 2013

Academic Editors: S. J. Lee, Q. Qu, and R. Solmaz

Copyright (C) 2013 Vikas Chawla. This is an open access article distributed under the Creative Commons Attribution License, which permits unrestricted use, distribution, and reproduction in any medium, provided the original work is properly cited.

\begin{abstract}
Nanostructured and conventional TiAlN and AlCrN coatings were deposited on ASTM-SA210 Grade A-1 boiler steel. The present work has been focused to characterize the conventional thick (by plasma spraying and gas nitrided) and nanostructured thin (by physical vapor deposition process) TiAlN and AlCrN coatings developed on ASTM-SA210 Grade A-1 boiler steel. The surface morphology of the coated samples was studied using FE-SEM with EDAX attachment, XRD analysis, AFM analysis, and the Xray mapping analysis. The presence of metal nitride phases as identified by XRD analysis indicates that the desired coatings were successfully developed. The bond strength, surface roughness, and microhardness of the gas nitrided plasma sprayed conventional coatings were measured. A good adhesion of the conventional thick TiAlN and AlCrN coatings was evident from bond test results.
\end{abstract}

\section{Introduction}

The boiler components are subjected to various types of degradation phenomenon such as high-temperature corrosion, erosion corrosion, overheating, solid particle abrasion and wear. High-temperature oxidation and erosion caused by the impact of fly ashes and unburnt carbon particles are the main problems to solve in these applications. Therefore, the development of wear and high-temperature oxidation protection systems in industrial boilers is a very important topic from both engineering and an economic perspective $[1,2]$. Present materials being capable of resisting erosive and corrosive environments are highly alloyed and thus expensive. In search for cost-effective solutions for erosion-corrosion problems, the effective method of erosion-corrosion prevention is to coat the alloy with a protective layer, which has been used in the current investigation.

The high-temperature protection system must meet several criteria: that is, it should provide adequate environmental resistance, be chemically and mechanically compatible with the substrate, and be practically applicable, reliable, and economically attractive [3]. The primary aim of the coating/surface treatment is the ability to produce a stable, slow-growing surface oxide providing a barrier between the coated alloy and the environment [4]. Recent studies show that $80 \%$ of the total cost for the protection of metals is related to coating application $[5,6]$.

According to DeMasi-Marcin and Gupta [7], physical vapor deposition and plasma spray (a thermal spray process) have been reported to be two major coating processing technologies which are used worldwide. The PVD processes have been successful in improving mechanical properties such as wear, friction, and hardness [8]. Their use as corrosionresistant coatings is also becoming widespread. Among the thermal spray coating processes, plasma spraying is reported to be versatile technology that has been successful as a reliable cost-effective solution for many industrial problems $[9,10]$. Since the commercialization of physical vapor deposited (PVD) TiN coatings in early 1980s, transition metal nitrides based hard coatings have been successfully used for the materials protection particularly to improve cutting tools lifetime [11].

In recent years, corrosion performance of nanostructured materials/coatings is a hot topic in corrosion field [12, 13]. Nanostructured materials as a new class of engineering materials indeed behave differently from their microscopic 
TABLE 1: Chemical composition (wt $\%$ ) of Grade A-1 boiler steel (ASTM-SA210 Grade A-1).

\begin{tabular}{lcccccc}
\hline Elements & $\mathrm{C}$ & $\mathrm{Mn}$ & $\mathrm{Si}$ & $\mathrm{S}$ & $\mathrm{P}$ & $\mathrm{Fe}$ \\
\hline Nominal & 0.27 & 0.93 & 0.1 & 0.058 & 0.048 & Bal. \\
Actual & 0.2768 & 0.6725 & 0.1725 & 0.00517 & 0.093 & Bal. \\
\hline
\end{tabular}

counterparts because their characteristic sizes are smaller than the characteristic length scales of physical phenomenon occurring in bulk materials [14]. As reported by Chawla et al. $[15,16]$, in the past decade, attractive properties associated with a nanostructure have been documented for bulk materials, where most of the research in the field of nanomaterials has been focused. Little work has been published on hightemperature corrosion behavior of nanostructured and conventional hard metal nitride coatings to the best of knowledge of the author. Therefore, these coatings were developed on the ASTM-SA210 Grade A-1 boiler steel, and their behavior was studied when exposed to high-temperature oxidation in air, molten salt environment, industrial environment, high temperature solid particle erosion, and simulated marine environment. The present work has been focused to characterize the conventional thick (by plasma spraying and gas nitrided) and nanostructured thin (by physical vapor deposition process) TiAlN and AlCrN coatings developed on ASTM-SA210 Grade A-1 boiler steel.

\section{Experimental Details}

2.1. Selection of Substrate and Sample Preparation. The boiler steel material "ASTM-SA210 Grade A-1" has been selected for the present study as the substrate material. Selection of candidate material for the study has been made after consultation with Guru Nanak Dev Thermal Plant, Bathinda (India). Grade A-1 has a wide range of applications in boilers, especially in the construction of their water walls. The actual chemical composition of the selected alloy has been determined with the help of Optical Emission Spectrometer (Thrmo Jarrel Ash, TJA181/81, USA), which is reported in Table 1 along with nominal chemical composition.

Specimens with dimensions of approximately $20 \mathrm{~mm} \times$ $15 \mathrm{~mm} \times 5 \mathrm{~mm}$ were cut from the alloy sheets. The specimens were polished using emery papers of $220,400,600$ grit sizes and subsequently on $1 / 0,2 / 0,3 / 0$, and $4 / 0$ grades. Then the samples were mirror polished using cloth polishing wheel machine with $1 \mu \mathrm{m}$ lavigated alumina powder suspension for deposition of nanostructured coatings and grit blasted with alumina powders (Grit 45) prior to the deposition of the conventional coatings by plasma spraying (a thermal spray process), for developing better adhesion between the substrates and the coatings. The specimens were prepared manually, and whole care was taken to avoid any structural changes in the specimens.

2.2. Development of Nanostructured Thin Coatings. The nanostructured thin TiAlN and AlCrN coatings, with a thickness around $4 \mu \mathrm{m}$, were deposited on the substrates at Oerlikon Balzers Coatings India Limited, Gurgaon, India.
TABLE 2: Summary of nanostructured thin coatings' deposition parameters.

\begin{tabular}{|c|c|c|}
\hline Coating parameters & $\begin{array}{c}\text { Nanostructured } \\
\text { TiAlN }\end{array}$ & $\begin{array}{c}\text { Nanostructured } \\
\text { AlCrN }\end{array}$ \\
\hline Machine used & $\begin{array}{l}\text { Standard balzers } \\
\text { rapid coating system } \\
\text { (RCS) machine }\end{array}$ & $\begin{array}{l}\text { Standard balzers } \\
\text { rapid coating system } \\
\text { (RCS) machine }\end{array}$ \\
\hline Made in & $\begin{array}{c}\text { Oerlikon Balzers, } \\
\text { Swiss }\end{array}$ & $\begin{array}{l}\text { Oerlikon Balzers, } \\
\text { Swiss }\end{array}$ \\
\hline Targets composition & $\mathrm{Ti}, \mathrm{Ti}_{50} \mathrm{Al}_{50}$ & $\mathrm{Al}_{70} \mathrm{Cr}_{30}$ \\
\hline Number of targets & $\operatorname{Ti}(02), \mathrm{Ti}_{50} \mathrm{Al}_{50}(04)$ & $\mathrm{Al}_{70} \mathrm{Cr}_{30}(06)$ \\
\hline Targets power & $3.5 \mathrm{KW}$ & $3.5 \mathrm{KW}$ \\
\hline Reactive gas & Nitrogen & Nitrogen \\
\hline Deposition pressure & $3.5 \mathrm{~Pa}$ & $3.5 \mathrm{~Pa}$ \\
\hline $\begin{array}{l}\text { Substrate bias } \\
\text { voltage }\end{array}$ & $-40 \mathrm{~V}$ to $-170 \mathrm{~V}$ & $-40 \mathrm{~V}$ to $-170 \mathrm{~V}$ \\
\hline Coating thickness & $4 \mu \mathrm{m} \pm 1 \mu \mathrm{m}$ & $4 \mu \mathrm{m} \pm 1 \mu \mathrm{m}$ \\
\hline
\end{tabular}

A front-loading Balzer's rapid coating system (RCS) machine (made in Oerlikon Balzers, Swiss) was used for the deposition of the coatings. The machine is equipped with 6 cathodic arc sources. In case of nanostructured thin TiAlN coatings, two of the six sources were used to deposit a thin, $0.3 \mu \mathrm{m}$ thick TiN sub-layer to improve adhesion of coating. The remaining four sources were employed to deposit the main layer of the coatings, which was obtained using customized sintered targets. Whereas in case of nanostructured thin AlCrN coating, all the six targets sources were employed to deposit the main layer of the coatings. The Oerlikon Balzers Coatings India Limited, Gurgaon, India has optimized the coating parameters for all the substrates. The compositions of the targets used, coating thickness and the summary of the process parameters, are presented in Table 2. For all coatings, argon (Ar) and pure nitrogen atmosphere were used during deposition. Prior to deposition all the substrates were cleaned in two steps: firstly with Ultrasonic Pre-Cleaner (made in Imeco, Pune, India) and secondly with Ultrasonic Cleaning Machine with 9 Tanks including hot air dryer (make Oerlikon Balzers Ltd. India) for $1.5 \mathrm{Hrs}$.

2.3. Development of Conventional Thick Coatings. Two types of coating powders, namely, Ti-50Al (50 Ti-50 Al Wt\%) and $\mathrm{Al}-30 \mathrm{Cr}$ (70 $\mathrm{Al}-30 \mathrm{Cr} \mathrm{Wt} \%$ ) were chosen for plasma spray deposition on the substrate. These powders were prepared in laboratory ball mill for $8 \mathrm{hrs}$ to form a uniform mixture from three types of commercially available alloy powders, namely, titanium powder with minimum assay 98.0\% (Art. 6322) supplied by Loba Chemie, Mumbai, India, aluminum powder with minimum assay $90.0 \%$ and size 200 mesh (Art. 37064 ) and chromium powder with minimum assay $99.0 \%$ and size 60 mesh (Art. 36054) supplied by S.D. Fine Chemical Limited, Mumbai, India. The coating work were carried out a commercial firm, namely, Anod Plasma Limited, Kanpur, India. They used $40 \mathrm{~kW}$ Miller Thermal (USA) plasma spray apparatus to apply the coatings. Argon was used as powder carrying and shielding gas. Standard spray parameters were 
TABLE 3: Parameters of the argon shrouded plasma spray process.

Arc current (A) 750

Arc voltage (V)

Powder feed rate (rev/min)

45

Spraying distance $(\mathrm{mm})$

5.2

Plasma arc gas (argon) pressure

$90-110$

Powder gas pressure

$58 \mathrm{psi}$

AVX gas pressure

$60 \mathrm{psi}$

$10 \mathrm{psi}$

designed by the previous firm for depositing the coatings in the present work. All the process parameters were kept constant throughout the coating process while spraying distance was maintained in a narrow range of $90-110 \mathrm{~mm}$. The process parameters for the shrouded plasma spray process employed for applying the coatings are summarized in Table 3.

Gas nitriding is a case hardening process whereby nitrogen is introduced into the surface of an alloy by holding it at a suitable temperature in contact with a nitrogenous gas, that is, nitrogen or ammonia. After reviewing the literature critically, it was decided to do the gas nitriding of the plasma sprayed conventional thick $\mathrm{Ti}-\mathrm{Al}$ and $\mathrm{Al}-\mathrm{Cr}$ coatings in the lab. The apparatus used for the gas nitriding process is shown in Figure 1, which consists of a long steel tube placed in a silicon tube furnace. In the front view (Figure 1), the steel tube is connected to the nitrogen cylinder for nitrogen supply, and in the rear view, the outlet of the nitrogen gas is through water for slow and constant discharge rate. The gas nitriding parameters were optimized after conducting several trials on plasma sprayed coated specimens. The process parameters employed for the gas nitriding are as summarized in Table 4.

2.4. Characterization of the Coatings. Field emission scanning electron microscope (FESEM, FEI, Quanta 200F Company) with EDAX Genesis software attachment (made in Czech Republic) is used to characterize the surface morphology of the coatings. SEM micrographs along with EDS spectrum were taken with an electron beam energy of $20 \mathrm{keV}$. The surface morphology (2D and 3D) of the thin films was also characterized by AFM (Model: NTEGRA, NT-MDT, Ireland) to calculate the surface roughness and particle size.

The coated specimens were subjected to XRD analysis using Bruker AXS D-8 advance diffractometer (Germany) with $\mathrm{Cu} \mathrm{K} \alpha$ radiation. The scan rate used was $2^{\circ} / \mathrm{min}$ and the scan range was from $20^{\circ}$ to $120^{\circ}$. The grain size of the thin films was estimated from Scherrer formula, as given in (1). In this expression, the grain size $D$ is along the surface normal direction, which is also the direction of the XRD diffraction vector:

$$
D=\frac{0.9 \lambda}{B \cos \theta}
$$

where $B$ is the corrected full-width at half maximum (FWHM) of a Bragg peak, $\lambda$ is the X-ray wavelength, and $\theta$ is the Bragg angle. $B$ is obtained from the equation $B^{2}=B^{2}{ }_{r}-$ $B^{2}$ strain $-C^{2}$, where $B_{r}$ is the FWHM of a measured Bragg peak, $B_{\text {strain }}=\varepsilon \tan \theta$ is the lattice broadening from the residual
TABLE 4: Parameters of the gas nitriding process.

\begin{tabular}{lc}
\hline Temperature & $650^{\circ} \mathrm{C}$ \\
Duration & $3 \mathrm{hrs}$ For Ti-Al coating \\
& $5 \mathrm{hrs}$ For Al-Cr coating \\
Discharge rate of nitrogen & $0.3 \mathrm{~L} / \mathrm{min}$ \\
\hline
\end{tabular}

strain $\varepsilon$ measured by XRD using the $\cos ^{2} \alpha \sin ^{2} \psi$ method, and $C$ is the instrumental line broadening. A Zeiss Axiovert 200 MAT inverted optical microscope, fitted with image software Zeiss Axiovision Release 4.1, was used for optical microscopy. The porosity measurements were made with image analyser, having software of Dewinter Materials Plus 1.01 based on ASTM B276. A PMP3 inverted metallurgical microscope was used to obtain the images.

The as-coated specimens were cut with a diamond cutter (Buehler's Precision Diamond Saw, Model ISOMET 1000, made in USA) across its cross-section and subsequently hot mounted in Buehler's transoptic powder (20-3400-080). Subsequently, the mounted specimens were polished manually using emery papers of 220, 400, and 600 grit sizes and subsequently on $1 / 0,2 / 0,3 / 0$, and $4 / 0$ grades. Finally, the specimens were mirror polished on a cloth polishing wheel machine with $0.05 \mu \mathrm{m}$ alumina powder suspension. The specimens were washed thoroughly with flowing water and dried in hot air to remove any moisture.

The thickness of the coatings was monitored during the coating processes. In case of plasma sprayed conventional thick coatings, the thickness was monitored with a Minitest2000 thin film thickness gauge (made in Germany, precision $\pm 1 \mu \mathrm{m})$. Efforts were made to obtain the coatings with uniform thickness. The thickness of some of the as-coated specimens (nanostructured as well as conventional coatings) was further verified by cutting along the cross-section and mounted (as explained previously). A Field emission scanning electron microscope (FE-SEM)(FEI Quanta 200F, made in Czech Republic) was used to obtain the back scattered electron (BSE) images.

The bond strength of the gas nitrided plasma sprayed coatings was tested using the ASTM standard C633-01. This test method covers the determination of the degree of adhesion (bonding strength) of a coating to a substrate or the cohesion strength of the coating in a tension normal to the surface. The test consists of coating one face of a substrate fixture, bonding this coating to the face of a loading fixture, and subjecting this assembly of coating and fixtures to a tensile load normal to the plane of the coating. A data acquisition system has continuously recorded the tensile load exerted by the machine. The surface roughness $\left(R_{a}\right)$ values of the gas nitrided plasma sprayed as coated specimens were measured using Surface Roughness Tester (Mitutoyo SJ-201, Japan). Each reported value of surface roughness $\left(R_{a}\right)$ is the mean of five observations taken at different locations. The centre line average (CLA) method was used to obtain the $R_{a}$ values.

$\mathrm{X}$-ray mapping analysis of the samples was done on field emission scanning electron microscope (FEI, Quanta 200F Company) for image acquisition entailed a backscattered 


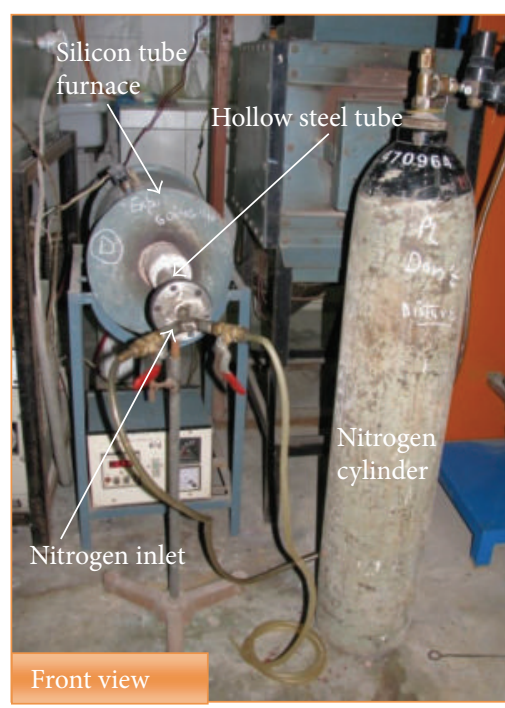

(a)

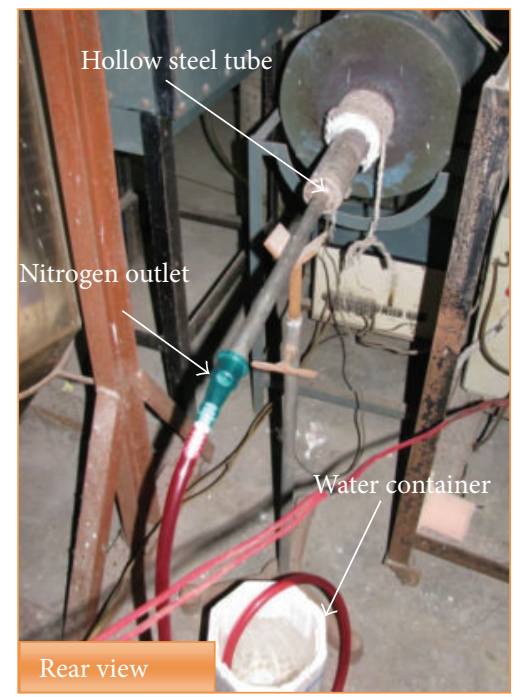

(b)

FIGURE 1: Front and rear views of the setup used for gas nitriding of the plasma sprayed conventional thick Ti-Al and Al-Cr coatings in the laboratory.

electron image (BSEI) and secondary electron image (SEI) mode. An accelerating voltage of $20-25 \mathrm{kV}$, a working distance of $9-10 \mathrm{~mm}$, and an image size of $1024 * 884$ pixels were used for getting quality images. Energy Dispersive X-ray Analysis (EDAX) and X-ray mapping were employed while imaging on FE-SEM was carried out to obtain elemental composition at different areas of the coating and surface morphology of the coatings, respectively. The specimen were silver pasted between samples and the stub in order to have conductivity, thereafter, gold-coated to facilitate elemental $\mathrm{X}$-ray mapping analysis of the different elements present across the coating. The selected area has three regions, that is, substrate, coating, and some epoxy region. X-ray mappings were obtained for all the elements of the substrate and the coatings, but only those mappings are reported which indicates the presence of some element.

For obtaining microhardness of the gas nitrided plasma sprayed conventional coatings, the specimens were cut, mounted, and polished (as explained polished). The microhardness of the as sprayed coatings was measured by using Miniload 2 Microhardness Tester (Leitz, Germany) fitted with a Vickers pyramidal diamond indenter. A $15 \mathrm{~g}(147.1 \mathrm{mN})$ load was applied to the indenter for penetration of as sprayed coatings. Hardness value was calculated from the relation $H v=1854.4 \times F / d^{2}$ where " $F$ " is the load in grams and " $d$ " is the diameter of the indenter in micrometer. Each reported value of the microhardness is the average value of five measurements.

\section{Observations and Results}

3.1. Visual Observations. The nanostructured thin (by Physical Vapor Deposition process) and conventional thick (by plasma spraying and gas nitriding) TiAlN and AlCrN coatings have been formulated successfully on ASTM-SA210
Grade A-1 boiler steel. The macrographs of as-coated Grade A-1 boiler steel are shown in Figure 2. It can be observed from the macrographs that the nanostructured thin TiAlN coating is violet grey in color and nanostructured thin $\mathrm{AlCrN}$ coating is light grey in color. Visual observations indicate that the surface of nanostructured coatings is smooth, whereas the surface of conventional thick coatings is rough. The color of the thick coatings appeared as grey with some bluish shining. Also, optical micrographs of the nanostructured and conventional coatings are shown in Figure 3 . The nanostructured coatings (Figures 3(a) and 3(b)) have uniform microstructure. It is evident from the microstructure that the coatings contain some pores and inclusions. In case of conventional thick coatings (Figures 3(c) and 3(d)), the massive microstructure can be observed with irregularly shaped grains.

\subsection{Surface Analysis}

3.2.1. X-Ray Diffraction Analysis (XRD). XRD diffractograms for nanostructured and conventional TiAlN and AlCrN coated ASTM-SA210 Grade A-1 boiler steel are depicted in Figure 4 on reduced scale. As indicated by the diffractograms in Figure 4; TiN and AlN are the main phases present in the nanostructured thin TiAlN coating. Further, in case of nanostructured $\mathrm{AlCrN}$ coating, the prominent phases are $\mathrm{CrN}$ and $\mathrm{AlN}$. The grain size of the nanostructured thin coatings was estimated from Scherrer formula; which is reported in Table 5. The calculated grain size for nanostructured thin TiAlN and AlCrN coatings is 16 and $26 \mathrm{~nm}$, respectively. Further, the main phases identified for the conventional thick TiAlN coating are $\mathrm{Al}_{2} \mathrm{O}_{3}, \mathrm{TiN}, \mathrm{Ti}_{3} \mathrm{Al}, \mathrm{AlN}$ and small peaks of $\mathrm{TiO}_{2}$ and $\mathrm{Fe}_{2} \mathrm{O}_{3}$. The phases identified in case of conventional thick AlCrN coating are $\mathrm{CrN}, \mathrm{AlN}$, and $\mathrm{Al}_{2} \mathrm{O}_{3}$ with minor peaks of $\mathrm{Cr}_{2} \mathrm{O}_{3}$. 


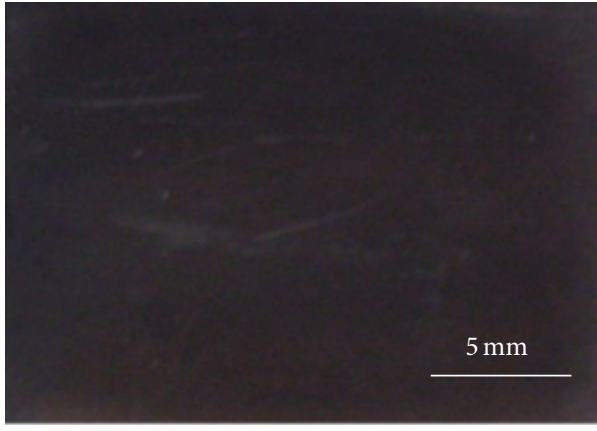

(a)

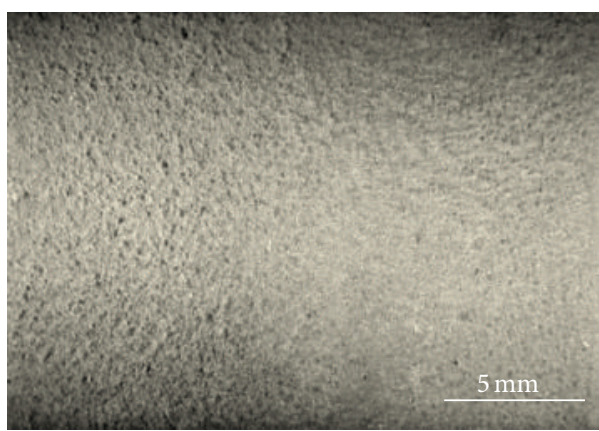

(c)

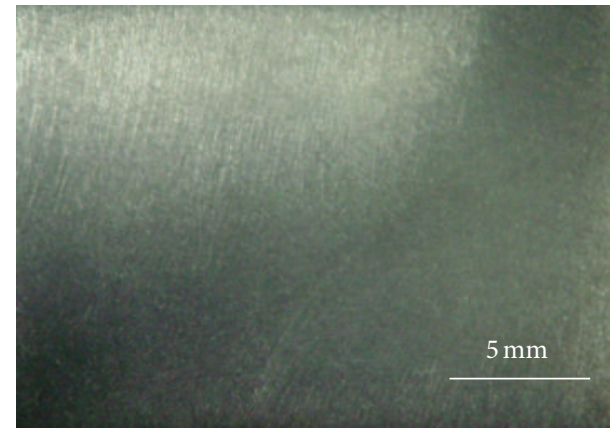

(b)

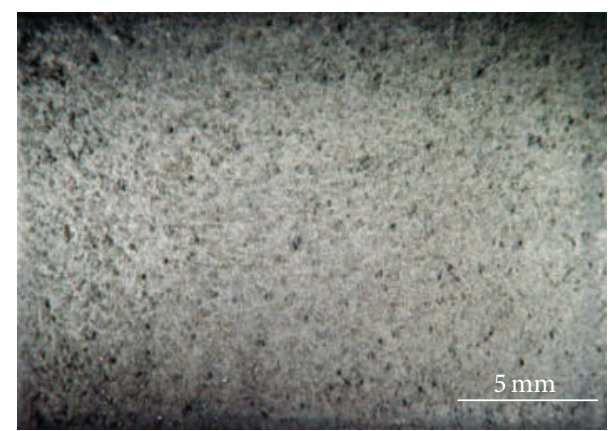

(d)

Figure 2: Surface macrographs for the as-coated ASTM-SA210 Grade A-1 boiler steel. (a) Nanostructured TiAlN coating, (b) nanostructured AlCrN coating, (c) conventional TiAlN coating, and (d) conventional AlCrN coating.

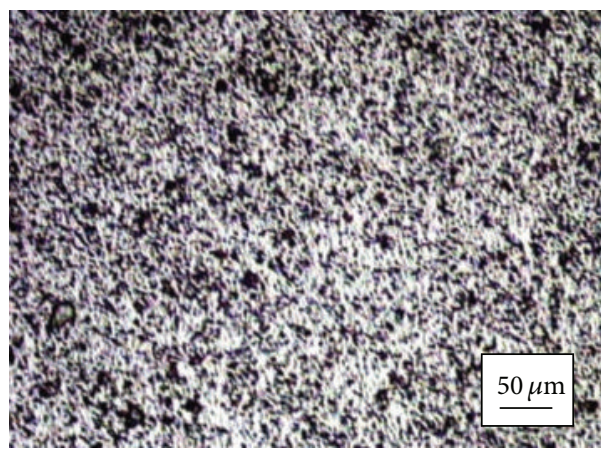

(a)

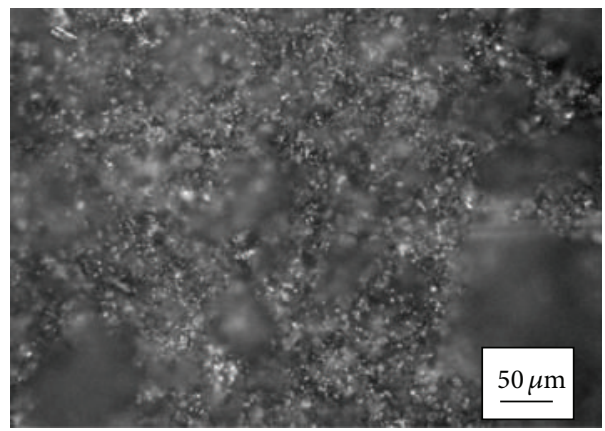

(c)

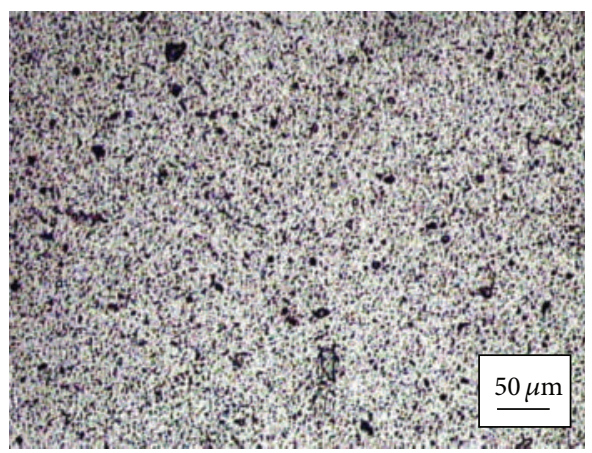

(b)

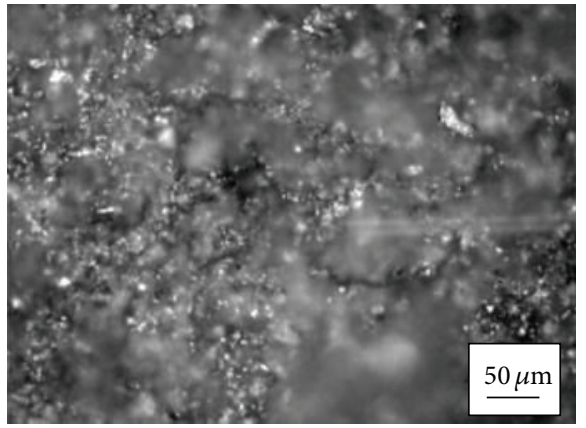

(d)

Figure 3: Optical micrograph (200x) of the surface of as-coated ASTM-SA210 Grade A-1 boiler steel. (a) Nanostructured TiAlN coating, (b) nanostructured AlCrN coating, (c) conventional TiAlN coating, and (d) conventional AlCrN coating. 
TABLE 5: Microstructural and mechanical properties of nanostructured thin TiAlN and AlCrN coated ASTM-SA210 Grade A-1 boiler steel.

\begin{tabular}{|c|c|c|c|c|c|c|}
\hline \multirow[b]{2}{*}{ Coating } & \multirow[b]{2}{*}{ Surface roughness $(\mathrm{nm})$} & \multicolumn{2}{|c|}{ Particle size (nm) } & \multirow[b]{2}{*}{ Porosity (\% age) } & \multirow[b]{2}{*}{ Coating thickness $(\mu \mathrm{m})$} & \multirow[b]{2}{*}{ Coating color } \\
\hline & & $\begin{array}{l}\text { Scherrer } \\
\text { formula }\end{array}$ & $\begin{array}{c}\text { AFM } \\
\text { analysis }\end{array}$ & & & \\
\hline $\begin{array}{l}\text { Nanostructured } \\
\text { TiAlN coating }\end{array}$ & 03.75 & 16 & 18 & $<0.5$ & 6.1 & Violet grey \\
\hline $\begin{array}{l}\text { Nanostructured } \\
\text { AlCrN coating }\end{array}$ & 06.10 & 26 & 28 & $<0.5$ & 4.2 & Light grey \\
\hline
\end{tabular}

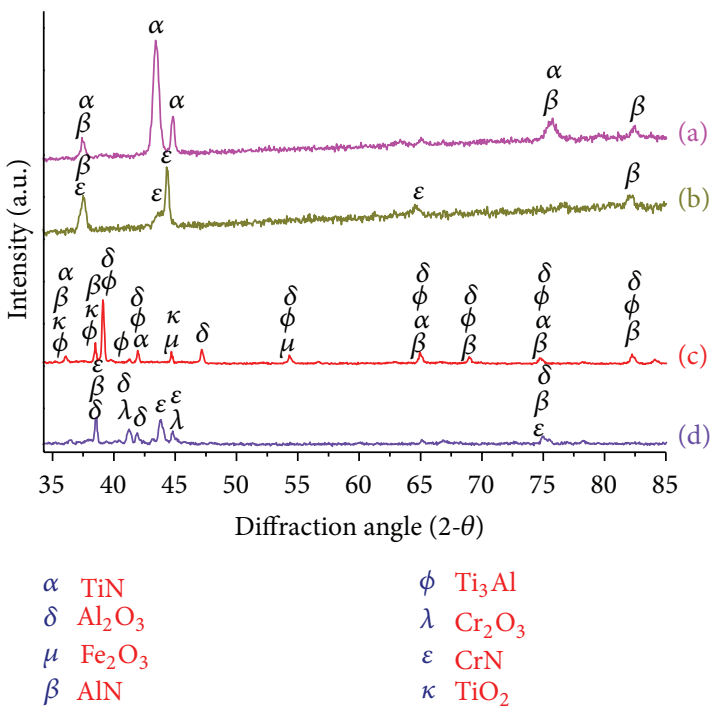

FIGURE 4: X-Ray Diffraction pattern of as-coated ASTM-SA210 Grade A-1 boiler steel. (a) Nanostructured TiAlN coating, (b) nanostructured AlCrN coating, (c) conventional TiAlN coating, and (d) conventional AlCrN coating.

3.2.2. Porosity Analysis. The porosity analysis is of prime importance in high temperature corrosion studies. The dense coatings are supposed to provide very good corrosion resistance as compared to porous coatings. The porosity measurements were made by PMP3 inverted metallurgical microscope with stereographic imaging. The porosity of nanostructured thin TiAlN and AlCrN coatings was found below $0.5 \%$ (Table 5 ). In case of conventional thick coatings; the porosity of as-sprayed $\mathrm{Ti}-\mathrm{Al}(2.30-4.25 \%)$ and $\mathrm{Al}-\mathrm{Cr}$ (2.00-4.30\%) coatings was also evaluated, which is reported in Table 6. A considerable decrease in the porosity had been observed after gas nitriding, and it was found to be less than $0.6 \%$ (Table 6).

3.2.3. AFM Analysis of the As-Deposited Nanostructured Thin Coatings. The surface topography of the nanostructured thin TiAlN and AlCrN coatings was studied using Atomic Force Microscope (AFM: NT-MDT: NTEGRA Model) in semicontact mode. Figure 5 shows the AFM surface morphology (2D and $3 \mathrm{D}$ ) of the nanostructured thin TiAlN and AlCrN coatings deposited on ASTM-SA210 Grade A-1 boiler steel. The difference in the morphology between the two coatings can be inferred by comparing the $2 \mathrm{D}$ images in Figures 5(a) and 5(c); however, a clearer comparison of the coatings could be afforded by viewing 3D images in Figures 5(b) and 5(d). As the axis scale indicates, the overall roughness of the nanostructured TiAlN coating (Figure 5(b)) is less than that of AlCrN coating (Figure 5(d)). The surface roughness and particle size in the coatings are analyzed by AFM analysis, reported in Table 5. The surface roughness in case of nanostructured TiAlN coating was observed to be $3.75 \mathrm{~nm}$ and $6.10 \mathrm{~nm}$ in case of nanostructured AlCrN coating (Table 5). The nanostructured thin TiAlN coating had shown lesser particle size $(18 \mathrm{~nm})$ as compared to nanostructured thin AlCrN coating $(28 \mathrm{~nm})$.

3.2.4. Surface Roughness $\left(R_{a}\right)$ Values of the Conventional Thick Coatings. The coating surface was very rough in case of conventional thick TiAlN and AlCrN coatings due to the presence of melted/partially melted particles and the roughness were found to be in the range of $10.35-15.13 \mu \mathrm{m}$ and $11.84-15.23 \mu \mathrm{m}$, respectively. The centre line average (CLA) method was used to obtain the $R_{a}$ values.

3.2.5. Evaluation of Microhardness and Bond Strength of the Conventional Thick Coatings. The hardness of the coatings has been measured along the cross-section of the conventional thick TiAlN and AlCrN coated Grade A-1 boiler steel. Figure 6 shows the microhardness profiles along the crosssection of the coatings as a function of distance from the coating-substrate interface. The critical hardness values of the substrate Grade A-1 boiler steel was found to be in the range 200-250 Hv. From the microhardness profiles (Figure 6) it is obvious that the conventional TiAlN coating has shown maximum microhardness of the order of 900-950 Hv. The conventional thick AlCrN coating has shown microhardness of the order of 600-700 Hv.

The bond strength of the conventional thick TiAlN and AlCrN coatings was measured on three specimens as per ASTM standard C633-01. The coatings failed at the substrate-coating interface while remaining attached to the adhesive (Figure 7). Average bond strength of 68.74 MPa and 54.69 MPa was observed in case of conventional TiAlN and AlCrN coatings, respectively (Table 6).

3.2.6. Surface Morphology of Coatings. FE-SEM micrographs along with EDS spectrum that reveal the surface morphology of the nanostructured and conventional TiAlN and AlCrN 


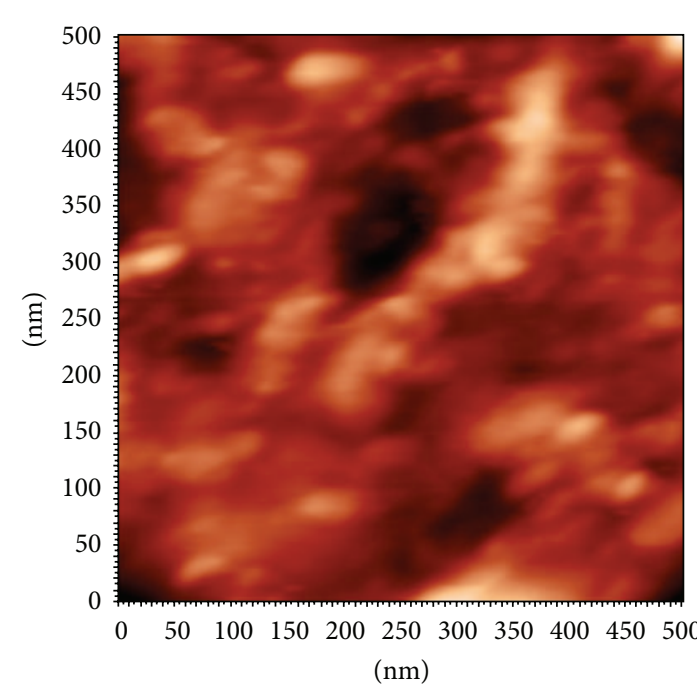

(a)

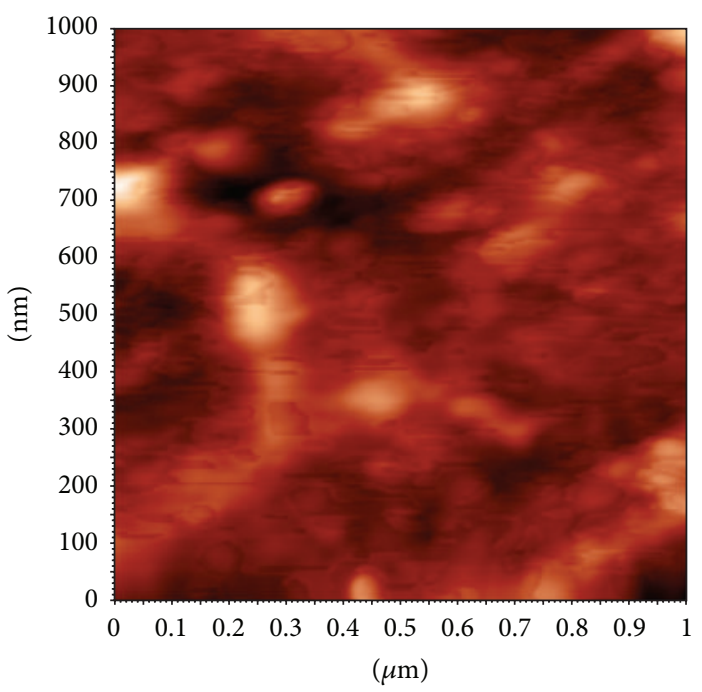

(c)
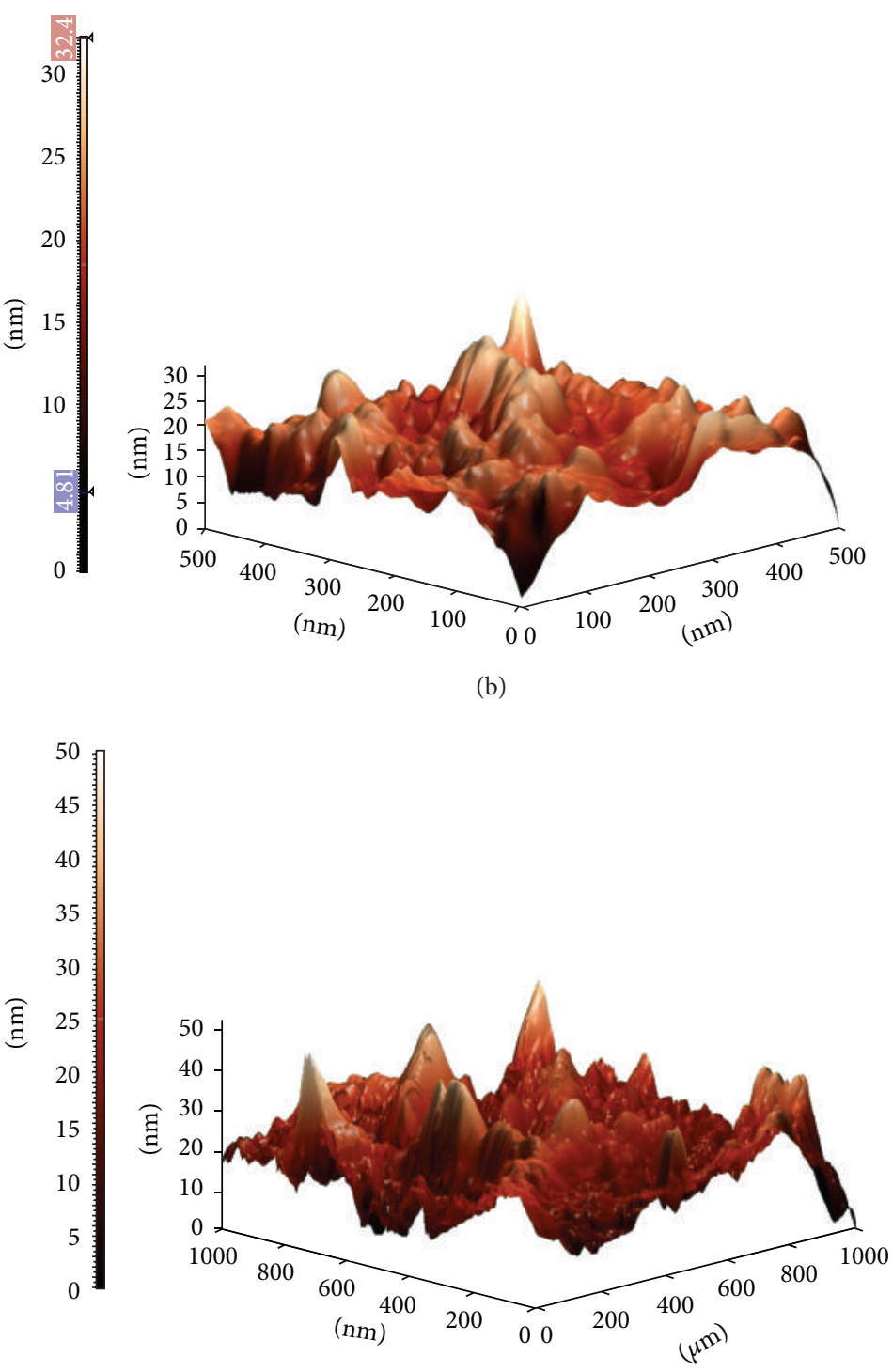

(d)

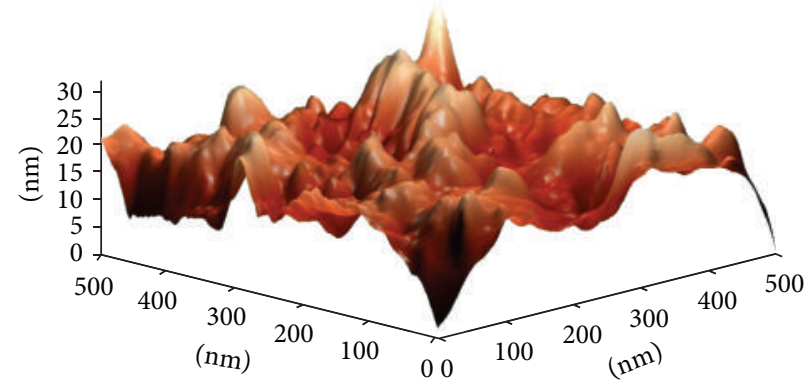

(b)

FIGURE 5: 2D and 3D AFM images for the as-coated ASTM-SA210 Grade A-1 boiler steel. (a) and (b) Nanostructured TiAlN coating, (c) and (d) nanostructured AlCrN coating.

coated ASTM-SA210 Grade A-1 boiler steel are shown in Figure 8. Micrograph (Figure 8(a)) for nanostructured thin TiAlN coating at higher magnification $(10000 \mathrm{x})$ indicates grey matrix with some black and white contrast regions. Dense structure with lower porosity is observed in the coating microstructure, and also it is free from cracks. EDAX analysis at point 1 and point 2 in Figure 8 indicates the presence of $\mathrm{Ti}, \mathrm{Al}$, and $\mathrm{N}$ with negligible amount of $\mathrm{Fe}$. The black colored areas revealed the higher amount of Ti and less concentration of $\mathrm{Al}$ as compared to the white contrast region. In case of nanostructured thin AlCrN coated Grade A-1 boiler steel, the FE-SEM micrograph indicates dense grey colored coating with tiny dark grey particles dispersed in the matrix. EDAX point analysis (points 3 and 4 in Figure 8 ) shows the coating 
TABLE 6: Microstructural and mechanical properties of conventional thick TiAlN and AlCrN coated ASTM-SA210 Grade A-1 boiler steel.

\begin{tabular}{|c|c|c|c|c|c|c|}
\hline \multirow[b]{2}{*}{ Coating } & \multirow[b]{2}{*}{ Surface roughness $(\mu \mathrm{m})$} & \multirow[b]{2}{*}{ Coating thickness $(\mu \mathrm{m})$} & \multicolumn{2}{|c|}{ Porosity (\% age) } & \multirow[b]{2}{*}{ Bond strength (MPa) } & \multirow[b]{2}{*}{ Coating color } \\
\hline & & & $\begin{array}{c}\text { As- } \\
\text { sprayed }\end{array}$ & $\begin{array}{l}\text { After gas } \\
\text { nitriding }\end{array}$ & & \\
\hline $\begin{array}{l}\text { Conventional } \\
\text { TiAlN coating }\end{array}$ & $10.35-15.13$ & 172 & $2.30-4.25$ & $<0.6$ & 68.74 & Grey \\
\hline $\begin{array}{l}\text { Conventional } \\
\text { AlCrN coating }\end{array}$ & $11.84-15.23$ & 166 & $2.00-4.30$ & $<0.6$ & 54.69 & Bluish grey \\
\hline
\end{tabular}

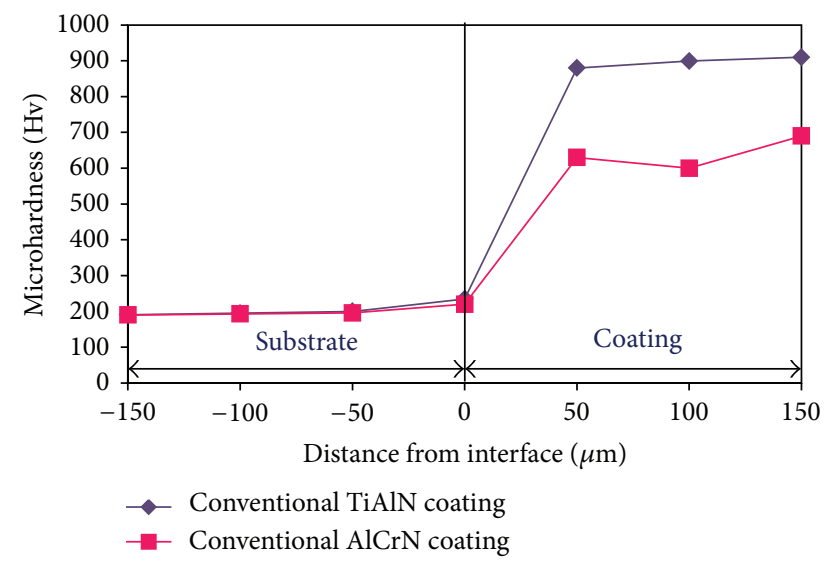

Figure 6: Microhardness profile across the cross-section for conventional TiAlN and conventional AlCrN coating on ASTM-SA210 Grade A-1 boiler steel.

\subsection{Cross-Sectional Analysis}

3.3.1. Coating Thickness. The as-coated samples were cut across the cross-section using Buehler Isomet 1000 precision saw and mounted in transoptic mounting resin and subsequently mirror-polished to obtain scanning electron back-scattered micrographs and X-ray mapping of different elements for coated and uncoated ASTM-SA210 Grade A-1 boiler steel. The coating thickness values were measured from SEM back-scattered micrographs as shown in Figure 9 and average coating thickness is reported in Table 6 . The measured average coating thickness values for nanostructured thin and conventional thick TiAlN and AlCrN coatings are $6.1,4.2,172$, and 166 and $122 \mu \mathrm{m}$, respectively.

3.3.2. X-Ray Mapping. BSEI and X-ray mapping analysis for nanostructured and conventional TiAlN and AlCrN coated ASTM-SA210 Grade A-1 boiler steel is shown in Figure 9. The BSEI and X-ray mapping analysis of the nanostructured TiAlN coated Grade A-1 boiler steel are presented in Figure 9(a). The X-ray mapping indicates presence of $\mathrm{Al}$ and Ti along with small amount of $\mathrm{N}$ in the coating, and no diffusion of $\mathrm{Fe}$ from the substrate has been observed. In case of nanostructured thin AlCrN coated Grade A-1 boiler steel, the BSEI and X-ray mapping are shown in Figure 9(b). The Xray mapping indicates the presence of $\mathrm{Al}$ and $\mathrm{Cr}$ along with some concentration of $\mathrm{N}$ in the coating, and no diffusion of Fe and other elements from the substrate has been observed.
In case of conventional thick TiAlN coated Grade A-1 boiler steel, Figure 9(c), Al- and Ti-rich coating along with negligible amount of $\mathrm{N}$ and $\mathrm{O}$ has been observed. The diffusion of $\mathrm{Fe}$ from the substrate has taken place as indicated by X-ray mapping analysis. Figure $9(\mathrm{~d})$ depicts the BSEI and X-ray mapping in case of conventional AlCrN coated Grade A-1 boiler steel. The coating is rich in $\mathrm{Al}$ and $\mathrm{Cr}$ with negligible presence of $\mathrm{N}$ and $\mathrm{O}$. The $\mathrm{X}$-ray mapping analysis indicates the presence of thin horizontal bands of $\mathrm{Al}$ and $\mathrm{O}$ in the coating.

\section{Discussion}

The nanostructured thin TiAlN and AlCrN coatings on ASTM-SA210 Grade A-1 boiler steel were obtained using a front-loading Balzer's rapid coating system (RCS) machine at Oerlikon Balzers Ltd. Gurgaon (India). The coating parameters were optimized. The coating thickness was measured along the cross-section for some randomly selected samples as has been reported in Table 5. The thin coatings were obtained and the coatings thickness was observed as 6.1 and $4.2 \mu \mathrm{m}$ in case of nanostructured TiAlN and AlCrN coatings, respectively. The surface appearance of nanostructured TiAlN coating was violet grey in color and light grey in case of nanostructured AlCrN coating (Figure 2). Figure 3 depicts the optical micrographs of the nanostructured thin coatings. The coatings were dense and have uniform microstructure. It is evident from the microstructure that the coatings contain some pores and inclusions (Figure 3 ). The negligible porosity values for as-coated nanostructured thin TiAlN and AlCrN coatings were observed, which were less than $0.5 \%$ (Table 5).

In case of conventional thick TiAlN and AlCrN coatings, the plasma spray coatings were obtained at Anod Plasma Ltd. Kanpur (India) using a $40 \mathrm{~kW}$ Miller Thermal Plasma Spray apparatus. The self-disintegration of thicker coatings usually restricts the thickness of the coatings [17]. The coating parameters were optimized. In the present study, it was possible to obtain a thickness in range of $150-200 \mu \mathrm{m}$ for the $\mathrm{Ti}-\mathrm{Al}$ and Al-Cr coatings. After coating deposition process, the gas nitriding was done in lab in order to obtain hard metal nitride coatings. The coating thickness was measured along the cross-section for some randomly selected samples as has been reported in Table 6 . The thick coatings were obtained, and the coatings thickness was observed as 172 and $166 \mu \mathrm{m}$ in case of conventional thick TiAlN and AlCrN, coatings respectively.

The surface appearance of conventional TiAlN and AlCrN coatings was grey with some bluish shining (Figure 2). 


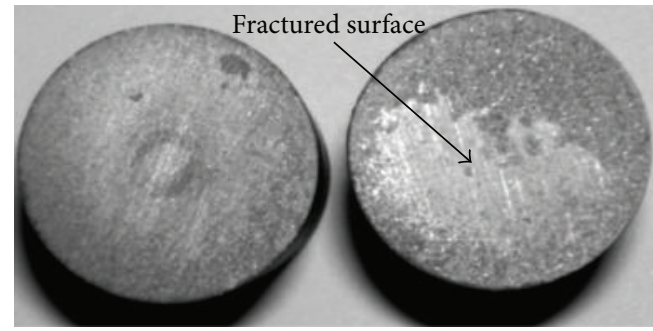

(a)

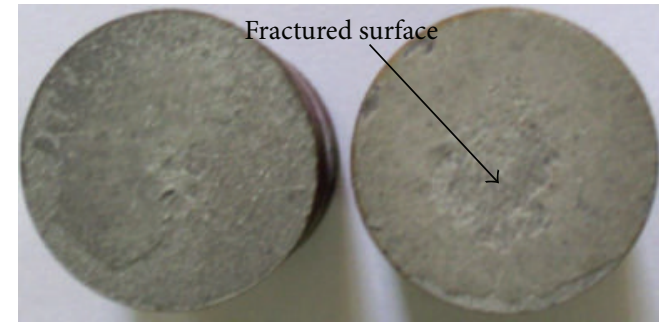

(b)

Figure 7: Fracture surfaces of a plasma sprayed gas nitride specimen after ASTM C633 tensile test. (a) Conventional TiAlN coating, (b) conventional AlCrN coating.

The surface of conventional thick coatings was rough. The measured porosity of plasma sprayed and gas nitrided coatings is given in Table 6 . The measured values of porosity (2.00-4.30\%) for as-sprayed conventional $\mathrm{Ti}-\mathrm{Al}$ and $\mathrm{Al}-\mathrm{Cr}$ coatings are almost in close agreement with the findings of Chen et al. [18], Erickson et al. [19], Hidalgo et al. [20, 21], Singh et al. [22], and Sidhu et al. [17, 23] for thermal plasma sprayed coatings, whereas after gas nitriding negligible porosity values were observed (Table 6), which were found to be less than $0.6 \%$ (Table 6). This may be due to the reason that gas nitriding process may have eliminated the microstructural inhomogeneities due to filling of pores and voids by nitrogen. Figure 3 depicts the optical micrographs of the conventional thick coatings. In case of conventional thick coatings (Figures 3(c) and 3(d)), the massive microstructure could be observed with irregularly shaped grains.

XRD diffractograms for nanostructured and conventional TiAlN and AlCrN coated ASTM-SA210 Grade A-1 boiler steel are depicted in Figure 4 on reduced scale. The phases identified by XRD analysis for nanostructured thin TiAlN coating are TiN and AlN. The phases analyzed are also in agreement with that reported by Yoo et al. [24], Falub et al. [25], and Man et al. [26]. Further, in case of nanostructured AlCrN coating, the prominent phases are $\mathrm{CrN}$ and $\mathrm{AlN}$ which are in agreement with the findings of Reiter et al. [27] and Endrino et al. [28]. The grain size (Table 1) of the nanostructured thin coatings was estimated from Scherrer formula [29] as follows:

$$
D=\frac{0.9 \lambda}{B \operatorname{Cos} \theta}
$$

where $\lambda, B$, and $\theta$ are the X-ray wavelength $\left(1.54056^{\circ} \mathrm{A}\right)$, Bragg diffraction angle, and line width at half maximum, respectively. The calculated grain size for nanostructured thin TiAlN and AlCrN coatings was 16 and $26 \mathrm{~nm}$, respectively. Oerlikon Balzers Ltd. Gurgaon (India) has provided the data regarding hardness of the as-coated nanostructured TiAlN and AlCrN coatings (Table 5). The coated layer on the steel substrate has provided higher hardness as compared to the substrate. In particular, nanostructured TiAlN coating showed higher hardness value than nanostructured AlCrN coating.

Figure 5 shows the AFM surface morphology (2D and 3D) of the nanostructured thin TiAlN and AlCrN coatings deposited on ASTM-SA210 Grade A-1 steel. The surface roughness and particle size in the coatings were also provided by AFM analysis, which are reported in Table 5 . As the axis scale indicates, the overall roughness of the nanostructured TiAlN coating (Figure 5(b)) is less than that of AlCrN coating (Figure 5(d)). The surface roughness in case of nanostructured TiAlN coating was observed to be $3.75 \mathrm{~nm}$ and $6.10 \mathrm{~nm}$ in case of nanostructured AlCrN coating (Table 5). The nanostructured thin TiAlN coating had shown smaller particle size $(18 \mathrm{~nm})$ as compared to nanostructured thin AlCrN coating $(28 \mathrm{~nm})$. The particle size determined by AFM analysis is in good agreement with the results obtained from Scherrer formula (as reported previously). The coating surface was very rough in case of conventional thick TiAlN and AlCrN coatings due to the presence of melted/partially melted particles, and the roughness was found to be in the range of $10.35-15.13 \mu \mathrm{m}$ and $11.84-15.23 \mu \mathrm{m}$, respectively. The centre line average (CLA) method was used to obtain the $R_{a}$ values.

Further, the main phases identified for the conventional thick TiAlN coating are $\mathrm{Al}_{2} \mathrm{O}_{3}, \mathrm{TiN}, \mathrm{Ti}_{3} \mathrm{Al}$, and $\mathrm{AlN}$ and small peaks of $\mathrm{TiO}_{2}$ and $\mathrm{Fe}_{2} \mathrm{O}_{3}$ as depicted in Figure 4. The phases identified in case of conventional thick AlCrN coating are $\mathrm{CrN}, \mathrm{AlN}$, and $\mathrm{Al}_{2} \mathrm{O}_{3}$ with minor peaks of $\mathrm{Cr}_{2} \mathrm{O}_{3}$ (Figure 4). The presence of metal nitride phases indicates that the gas nitriding process has successfully produced the desired coatings. Further, the phases analyzed are also in agreement with that reported by Adachi and Nakata [30]. They have worked on $\mathrm{Ti}, \mathrm{Al}$, and $\mathrm{Ti}-\mathrm{Al}$ based coatings under various conditions, that is, air and/or nitrogen environment by plasma spraying technique. Further, they have reported that the X-ray diffraction pattern for Ti-50 mass\% $\mathrm{Al}$ mixed powder sprayed coatings detected $\mathrm{Al}$, and $\mathrm{TiN}_{0.3}, \mathrm{Ti}(\mathrm{N}, \mathrm{O})$ and peaks of synthesized phase of $\mathrm{Ti}_{3} \mathrm{Al}$. The sprayed $\mathrm{Ti}$ coating had a porous structure and included cracks and pores in high density. The sprayed $\mathrm{Al}$ coating had a dense microstructure. And the sprayed Ti-50 mass\% Al coatings had a dense laminated structure composed of Ti compounds phase and $\mathrm{Al}$ phase. According to them, the formula of $\mathrm{Ti}_{3} \mathrm{Al}$ formation is given by

$$
3 \mathrm{Ti}+\mathrm{Al}=\mathrm{Ti}_{3} \mathrm{Al}, \quad \Delta G^{f}=-29633.6+6.70801 \mathrm{~T} / \mathrm{K},
$$



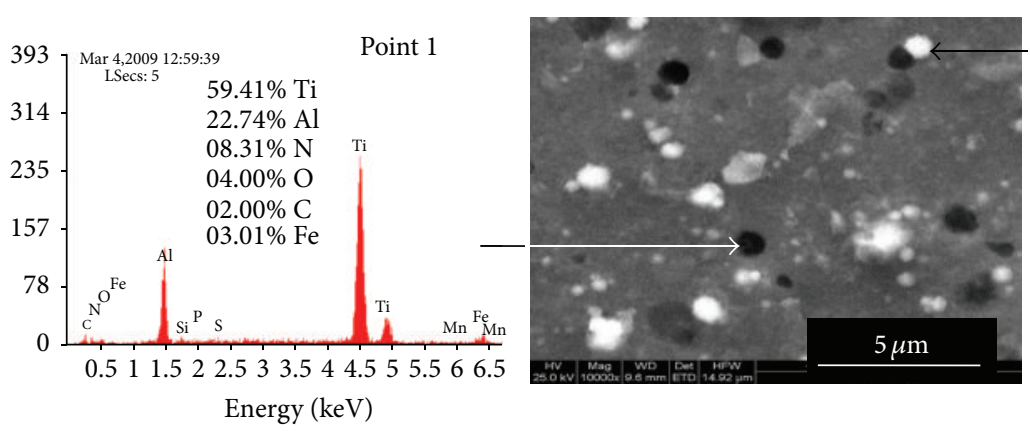

(a)

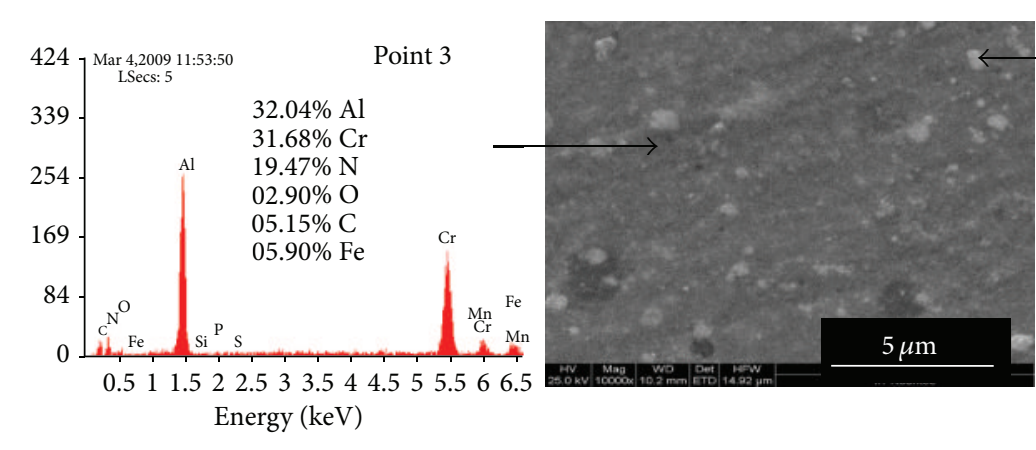

(b)

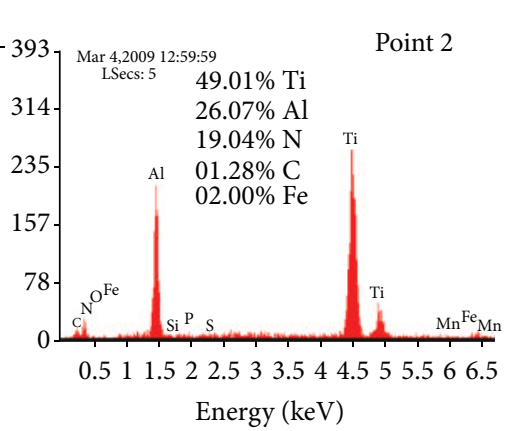

Energy $(\mathrm{keV})$
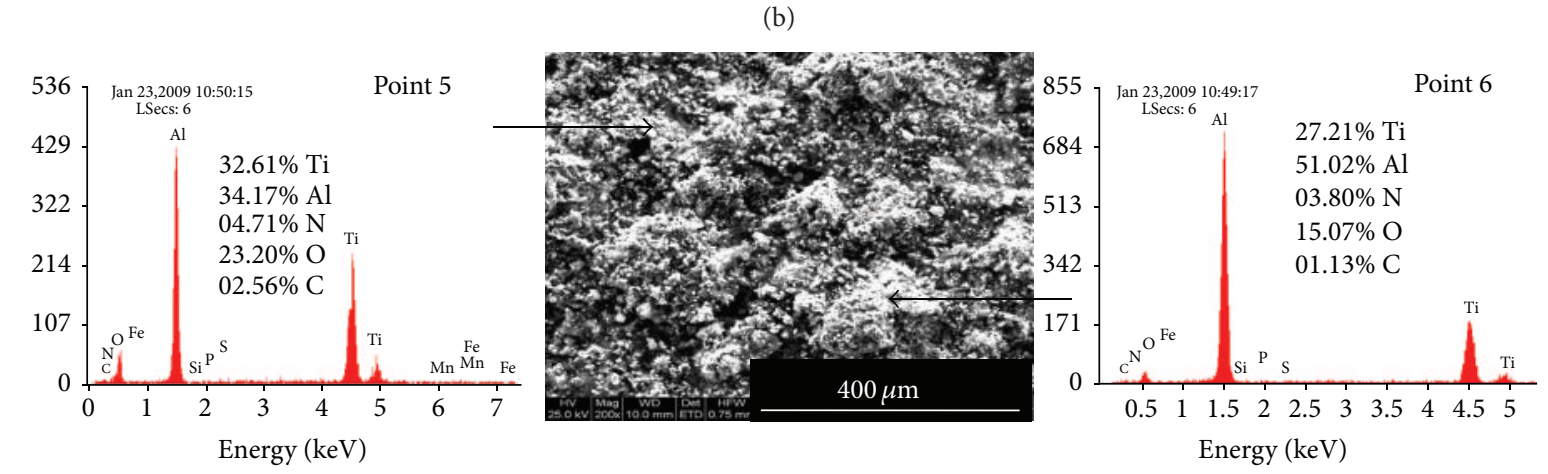

(c)
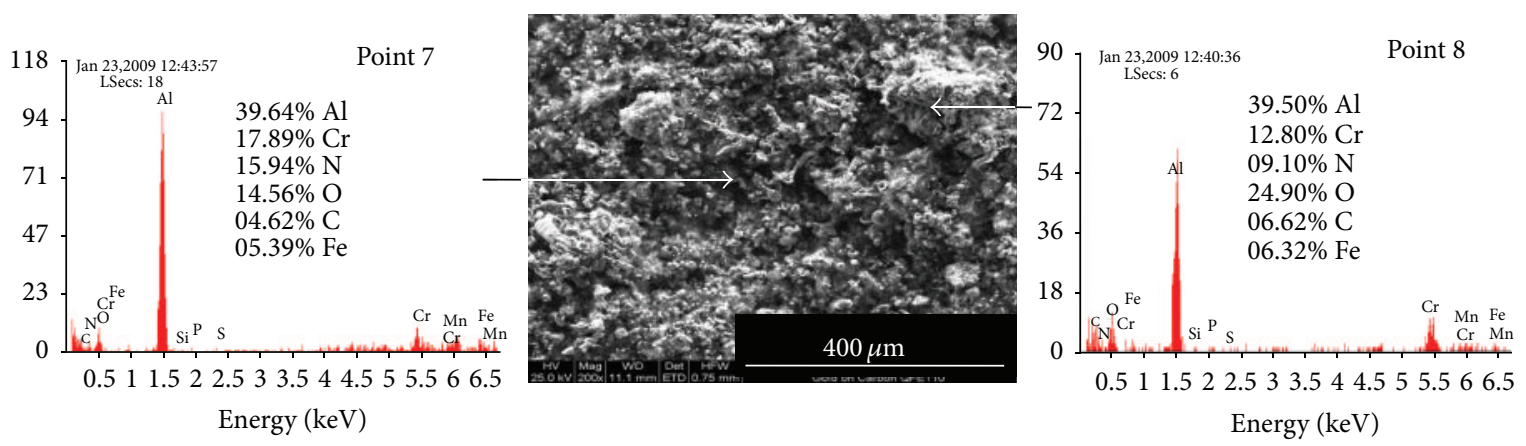

(d)

FIGURE 8: Surface-scale morphology and EDAX patterns from different spots on as-coated ASTM-SA210 Grade A-1 boiler steel. (a) Nanostructured TiAlN coating, (b) nanostructured AlCrN coating, (c) conventional TiAlN coating, and (d) conventional AlCrN coating.

where $\Delta G^{f}$ is the Gibbs energy of $\mathrm{Ti}_{3} \mathrm{Al}$ formation $\left(\mathrm{Jmol}^{-1}\right)$. That is, from the view of the thermodynamics, $\mathrm{Ti}_{3} \mathrm{Al}$ can be easily formed from Ti with Al. The pressures of $\mathrm{O}_{2}$ and $\mathrm{N}_{2}$ in the atmosphere are much higher than the equilibrium pressure $\mathrm{O}_{2}$ and $\mathrm{N}_{2}$ to form $\mathrm{Ti}_{3} \mathrm{Al}$ from $\mathrm{TiO}$ with $\mathrm{Al}$ and $\mathrm{TiN}$ with $\mathrm{Al}[30]$. So, $\mathrm{Ti}_{3} \mathrm{Al}$ cannot be formed thermodynamically from $\mathrm{TiO}$ with $\mathrm{Al}$ or $\mathrm{TiN}$ with $\mathrm{Al}$ under the condition of spraying in the air atmosphere. This phenomenon indicates 

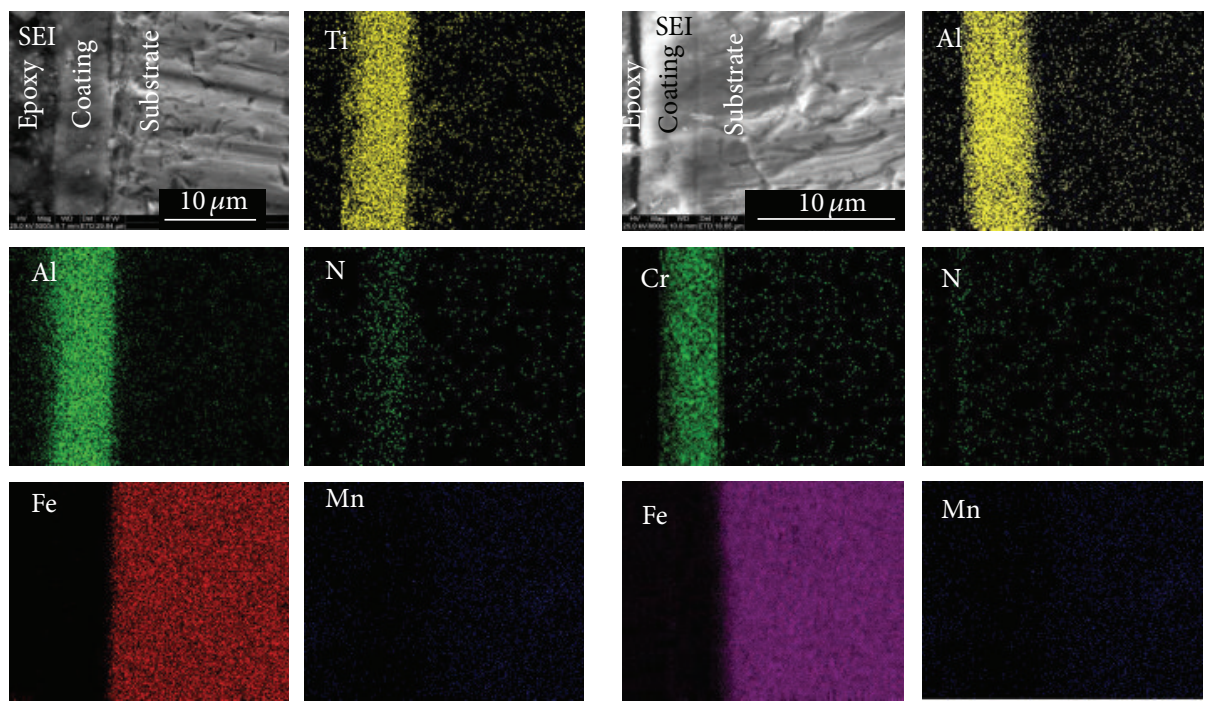

(a)

(b)
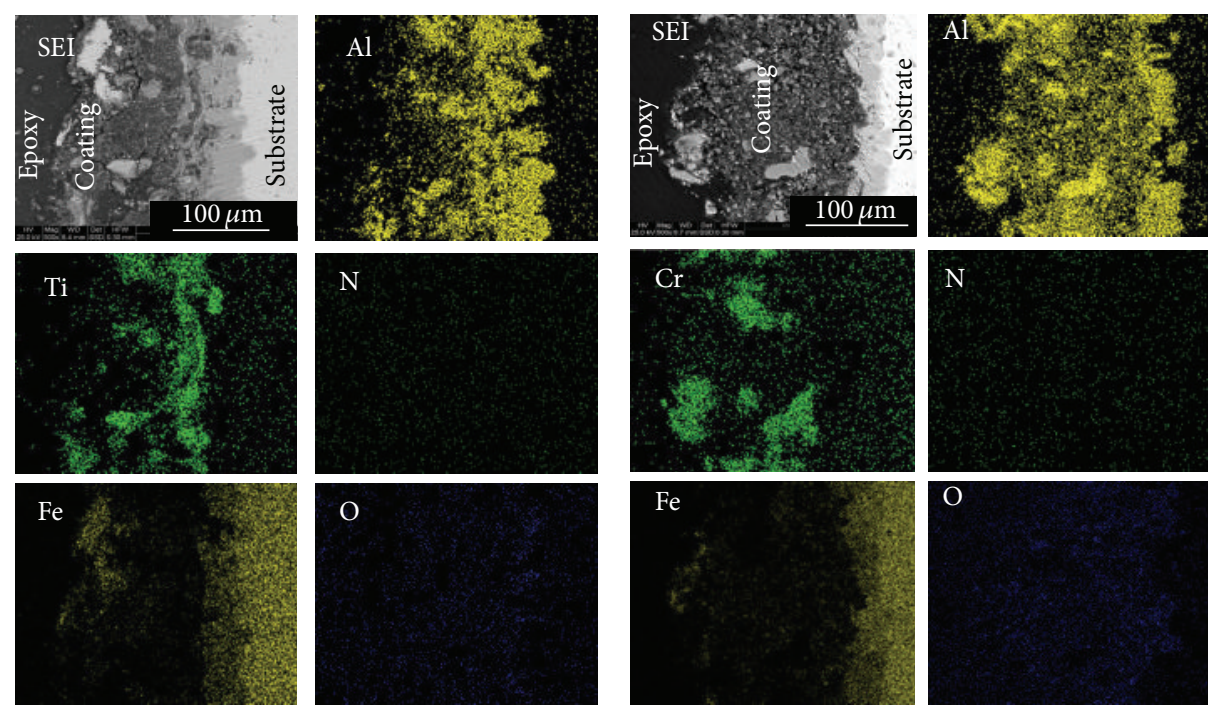

(c)

(d)

FIGURE 9: (a) Composition image (SEI) and X-ray mapping of the cross-section of as-coated nanostructured TiAlN coating on ASTM-SA210 Grade A-1 boiler steel. (b) Composition image (SEI) and X-ray mapping of the cross-section of as-coated nanostructured AlCrN coating on ASTM-SA210 Grade A-1 boiler. (c) Composition image (SEI) and X-ray mapping of the cross-section of as-coated conventional TiAlN coating on ASTM-SA210 Grade A-1 boiler steel. (d) Composition image (SEI) and X-ray mapping of the cross-section of as-coated conventional AlCrN coating on ASTM-SA210 Grade A-1 boiler steel.

that $\mathrm{Ti}_{3} \mathrm{Al}$ would be synthesized from $\mathrm{Ti}$ and $\mathrm{Al}$ particles dynamically during flight [30]. The reaction would proceed at the interface of the Ti particle contacted with the Al particle. The formulas of compounds formation can be described as follows:

$$
\begin{gathered}
\mathrm{Ti}+\frac{1}{2} \mathrm{~N}_{2}+\frac{1}{2} \mathrm{O}_{2}=\mathrm{Ti}(\mathrm{N}, \mathrm{O}), \\
\mathrm{Ti}+\mathrm{N}_{2}=\mathrm{TiN}_{0: 3}, \\
3 \mathrm{Ti}+\mathrm{Al}=\mathrm{Ti}_{3} \mathrm{Al} .
\end{gathered}
$$

Conclusively, Adachi and Nakata [30] have reported that the formation of the $\mathrm{Ti}-\mathrm{Al}$ sprayed coating on the substrate would proceed as follows. At first, the compounds of Ti oxide and nitride in the fused particles would be solidified almost as soon as they adhere to the substrate, as the melting points of TiO and TiN are $2023 \mathrm{~K}$ and $3223 \mathrm{~K}$, respectively, which are much higher than that of $\mathrm{Al}, 933 \mathrm{~K}$. Then, cracks and pores between the Ti compound layers would be filled with the melting Al particles, and the coating finally became solidified as a whole.

Hardness is the most frequently quoted mechanical property of the coatings [31]. The observed microhardness values (Figure 6) for the conventional coatings are within the range of microhardness values reported for plasma coatings by Adachi and Nakata [30], Vuoristo et al. [32], 
Chen and Hutchings [33], and Westergård et al. [34]. Microhardness plots (Figure 6) indicate some increase in the microhardness of substrate steel at the substrate coating interface. The hardening of the substrates as observed in the current study might have occurred due to the highspeed impact of the coating particles during plasma spray deposition. The effect has also been reported by Hidalgo et al. [20, 21, 35, 36] and Sidhu et al. [17, 23]. The observed nonuniformity in the hardness values along the thickness of the coatings may be due to the microstructural changes along the cross-section of the coatings [37]. Moreover, the microhardness and other properties of the thermal spray coatings are anisotropic because of their typical splat structure and directional solidification [31].

The bond strength of the conventional thick TiAlN and AlCrN coatings was measured on three specimens as per ASTM standard C633-01. The coatings failed at the substrate-coating interface while they remain attached to the adhesive (Figure 7). Average bond strength of 68.74 MPa and $54.69 \mathrm{MPa}$ was observed in case of conventional TiAlN and AlCrN coatings, respectively (Table 6). The bond strength in case of conventional TiAlN coatings $(68.74 \mathrm{MPa})$ is in good agreement (slightly more) with the results reported by Adachi and Nakata [30] regarding their work based on plasma sprayed Ti-Al coatings (60 $\mathrm{MPa})$.

FE-SEM micrographs along with EDS spectrum that reveal the surface morphology of the nanostructured and conventional TiAlN and AlCrN coated ASTM-SA210 Grade A-1 boiler steel are shown in Figure 8. Surface EDAX analysis is supported by XRD (Figure 4) and X-ray mapping analysis (Figure 9) in all coatings. The presence of $\mathrm{Ti}, \mathrm{Al}$, and $\mathrm{N}$ with negligible amount of Fe (in nanostructured TiAlN coating), $\mathrm{Al}, \mathrm{Cr}$, and $\mathrm{N}$ along with small amount of Fe and oxygen (in nanostructured TiAlN coating) the higher concentration of $\mathrm{Ti}$ and $\mathrm{Al}$ in the coating along with some amount of $\mathrm{N}$ and oxygen (in conventional TiAlN coating) and $\mathrm{Al}$ and $\mathrm{Cr}$ along with $\mathrm{N}$ and oxygen (in conventional AlCrN coating); is revealed by surface EDAX analysis (Figure 8). Also, the XRD analysis (Figure 4) indicates the presence of the oxide phases in the coatings, that is, $\mathrm{Al}_{2} \mathrm{O}_{3}, \mathrm{TiO}_{2}$, and $\mathrm{Fe}_{2} \mathrm{O}_{3}$ in case of conventional TiAlN coating and the presence of $\mathrm{Al}_{2} \mathrm{O}_{3}$ and $\mathrm{Cr}_{2} \mathrm{O}_{3}$ in case of conventional AlCrN coatings. According to Bluni and Mardar [38] the oxides may have formed due to the in-flight oxidation during spraying process and/or preexisting in the feed material. The latter reason for the oxides formation in the structure of coatings under study looks to be more relevant as the chances of inflight oxidation are meager in case of the shrouded plasma spraying.

Deshpande et al. [39] proposed that, during in-flight oxidation, a layer of oxide is formed on the molten particle due to chemical reactions between the surface of the liquid phase and oxygen or due to diffusion of oxygen into the liquid. The turbulent mixing of the liquid part of the powder particle during its flight destroys the surface layer of oxides and causes the oxides to be distributed more uniformly through the bulk volume of the particle. However, when temperature of the particle starts dropping during later part of the flight, these oxides tend to solidify and a thin oxide shell would be formed around the droplet.
The oxidation time during thermal spray coating is short typically less than $0.01 \mathrm{~s}$ and can occur in either the solid or molten state. The oxidation of coatings is not always harmful; it is equally important to control and understand the different aspects of oxidation of coatings; therefore, it is important to find an optimum level for oxidation of coatings [40-42]. The diffusion of Fe from the substrate to the coating (in conventional coatings) was identified by XRD and X-raymapping analysis. This type of diffusion of the base metal component into the coating has also been observed by Wang et al. [43]. They have reported the penetration of Co from the base alloy to the coating after heat treatment of coatings for 2 hrs at $1050^{\circ} \mathrm{C}$.

\section{Conclusions}

The nanostructured thin TiAlN and AlCrN coatings (by physical vapour deposition process at Oerlikon Balzers Ltd. Gurgaon, India) and conventional thick TiAlN and AlCrN coatings (by plasma spraying process at Anod Plasma Ltd. Kanpur, India; followed by gas nitriding process) were successfully deposited on ASTM-SA210 Grade A-1 boiler steel. The coatings were characterized for their microstructural features and hardness in present work. The following observations were made based on the present study.

(1) The nanostructured thin TiAlN and AlCrN coatings exhibited negligible porosity values for as-coated, which were less than $0.5 \%$. The conventional TiAlN and AlCrN coatings showed higher porosity values (2.00-4.30\%) for as-sprayed conventional Ti-Al and Al-Cr coatings which after gas nitriding were found to be less than $0.6 \%$.

(2) The phases identified by XRD analysis for nanostructured thin TiAlN coating are TiN and AlN. Further, in case of nanostructured AlCrN coating, the prominent phases are $\mathrm{CrN}$ and $\mathrm{AlN}$. The main phases identified (by XRD analysis) for the conventional thick TiAlN coating were $\mathrm{Al}_{2} \mathrm{O}_{3}, \mathrm{TiN}, \mathrm{Ti}_{3} \mathrm{Al}$, ands $\mathrm{AlN}$ and small peaks of $\mathrm{TiO}_{2}$ and $\mathrm{Fe}_{2} \mathrm{O}_{3}$. The phases identified in case of conventional thick AlCrN coating were $\mathrm{CrN}$, $\mathrm{AlN}$, and $\mathrm{Al}_{2} \mathrm{O}_{3}$ with minor peaks of $\mathrm{Cr}_{2} \mathrm{O}_{3}$. The presence of metal nitride phases indicates that the gas nitriding process has successfully produced the desired coatings.

(3) The grain size (calculated by Scherrer formula from XRD plot) for nanostructured thin TiAlN and AlCrN coatings was 16 and $26 \mathrm{~nm}$, respectively. The particle size determined by AFM analysis is in good agreement with the results obtained from Scherrer formula. From AFM analysis, the particle size observed for nanostructured thin TiAlN and AlCrN coatings was $18 \mathrm{~nm}$ and $28 \mathrm{~nm}$ respectively.

(4) The surface roughness in case of nanostructured TiAlN coating was observed as $3.75 \mathrm{~nm}$ and $6.10 \mathrm{~nm}$ in case of nanostructured AlCrN coating, as observed by AFM analysis. The coating surface was very rough 
in case of conventional thick TiAlN and AlCrN coatings due to the presence of melted/partially melted particles, and the roughness was found to be in the range of $10.35-15.13 \mu \mathrm{m}$ and $11.84-15.23 \mu \mathrm{m}$, respectively. The centre line average (CLA) method was used to obtain the $R_{a}$ values.

(5) A good adhesion of the conventional thick TiAlN and AlCrN coatings was evident from bond test results. Average bond strength of $68.74 \mathrm{MPa}$ and $54.69 \mathrm{MPa}$ Psi was observed in case of conventional TiAlN and AlCrN coatings, respectively.

\section{References}

[1] V. H. Hidalgo, J. B. Varela, A. C. Menéndez, and S. P. Martínez, "High temperature erosion wear of flame and plasma-sprayed nickel-chromium coatings under simulated coal-fired boiler atmospheres," Wear, vol. 247, no. 2, pp. 214-222, 2001.

[2] V. H. Hidalgo, F. J. B. Varela, A. C. Menéndez, and S. P. Martínez, "A comparative study of high-temperature erosion wear of plasma-sprayed $\mathrm{NiCrBSiFe}$ and $\mathrm{WC}-\mathrm{NiCrBSiFe}$ coatings under simulated coal-fired boiler conditions," Tribology International, vol. 34, no. 3, pp. 161-169, 2001.

[3] B. S. Sidhu, D. Puri, and S. Prakash, "Mechanical and metallurgical properties of plasma sprayed and laser remelted $\mathrm{Ni}$ 20Cr and Stellite-6 coatings," Journal of Materials Processing Technology, vol. 159, no. 3, pp. 347-355, 2005.

[4] J. R. Nicholls, N. J. Simms, W. Y. Chan, and H. E. Evans, "Smart overlay coatings: concept and practice," Surface and Coatings Technology, vol. 149, no. 2-3, pp. 236-244, 2002.

[5] V. Chawla, S. Prakash, D. Puri, and B. Singh, "State of Art: corrosion in thermal power plants and preventive measures: a review," in Proceedings of the National Conference on Advancement \& Futuristic Trends in Mechanical \& Materials Engineering, G.Z.S. College of Engineering anf Technology, Bathinda, India, October 2006.

[6] V. Chawla, S. Prakash, D. Puri, and B. Singh, "Plasma sprayed coatings for protection against hot Corrosion: a review," in Proceedings of the of International Conference on Advances in Mechanical Engineering (AME '06), Baba Banda Singh Bahadaur College of Engineering, Fatehgarh Sahib, India, December 2006.

[7] J. T. DeMasi-Marcin and D. K. Gupta, "Protective coatings in the gas turbine engine," Surface and Coatings Technology, vol. 68-69, no. C, pp. 1-9, 1994.

[8] H. O. Pierson, "CVD/PVD coatngs," in ASM Handbook: Corrosion, J. R. Davis, Ed., vol. 13, pp. 456-458, ASM International, Materials Park, Ohio, USA, 1987.

[9] P. Fauchais, "Topical Review: understanding plasma spraying," Journal of Physics D, vol. 37, no. 9, pp. R86-R108, 2004.

[10] V. Chawla, S. Prakash, D. Puri, and B. Singh, "State of art: hot corrosion: a review," in Proceedings of the Global Conference on Production and Industrial Engineering (CPIE '07), B.R. Ambedkar National Institute of Technology, Jalandhar, India, March 2007.

[11] J. L. He, K. C. Chen, C. C. Chen, A. Leyland, and A. Matthews, "Cyclic oxidation resistance of Ni-Al alloy coatings deposited on steel by a cathodic arc plasma process," Surface and Coatings Technology, vol. 135, no. 2-3, pp. 158-165, 2001.

[12] V. Chawla, S. Prakash, D. Puri, and B. Singh, "Corrosion behaviour of nanostructured TiAlN and AlCrN hard coatings on Superfer $800 \mathrm{H}$ superalloy in simulated marine environment," Journal of Minerals and Materials Characterization and Engineering, vol. 8, no. 9, pp. 693-700, 2009.

[13] V. Chawla, D. Puri, S. Prakash, A. Chawla, and B. Singh, "Characterization and comparison of corrosion behaviour of nanostructured TiAlN and AlCrN coatings on Superfer $800 \mathrm{H}$ (INCOLOY $800 \mathrm{H}$ ) substrate," Journal of Minerals and Materials Characterization and Engineering, vol. 8, no. 9, pp. 715-727, 2009.

[14] V. Chawla, S. Prakash, and B. S. Sidhu, "State of the art: applications of mechanically alloyed nanomaterials: a review," Materials and Manufacturing Processes, vol. 22, no. 4, pp. 469473, 2007.

[15] V. Chawla, B. S. Sidhu, D. Puri, and S. Prakash, "Performance of plasma sprayed nanostructured and conventional coatings," Journal of the Australian Ceramic Society, vol. 44, no. 2, pp. 5662, 2008 .

[16] V. Chawla, S. Prakash, D. Puri, and B. Singh, "State of art: plasma sprayed nanostructured coatings: a review," Materials Forum, vol. 32, pp. 137-143, 2008.

[17] B. S. Sidhu, D. Puri, and S. Prakash, "Characterisations of plasma sprayed and laser remelted NiCrAlY bond coats and $\mathrm{Ni}_{3} \mathrm{Al}$ coatings on boiler tube steels," Materials Science and Engineering A, vol. 368, no. 1-2, pp. 149-158, 2004.

[18] H. C. Chen, Z. Y. Liu, and Y. C. Chuang, "Degradation of plasma-sprayed alumina and zirconia coatings on stainless steel during thermal cycling and hot corrosion," Thin Solid Films, vol. 223, no. 1, pp. 56-64, 1993.

[19] L. C. Erickson, R. Westergård, U. Wiklund, N. Axén, H. M. Hawthorne, and S. Hogmark, "Cohesion in plasma-sprayed coatings: a comparison between evaluation methods," Wear, vol. 214 , no. 1, pp. 30-37, 1998.

[20] V. Higuera Hidalgo, F. J. Belzunce Varela, and A. Carrilez Menendez, "Characterization and high temperature behaviour of thermal sprayed coatings used in boilers," in Proceedings of the 15th International Thermal Spray Conference, pp. 617-621, Nice, france, May 1998.

[21] V. H. Hidalgo, F. J. B. Varela, S. P. Martinez, and S. G. Espana, "Characterization and high temperature behaviour of $\mathrm{Cr}_{3} \mathrm{C}_{2}$ NiCr plasma sprayed coatings," in Proceedings of the United Thermal Spray Conference, pp. 683-686, Germany, 1999.

[22] H. Singh, D. Puri, and S. Prakash, "Some studies on hot corrosion performance of plasma sprayed coatings on a $\mathrm{Fe}$ based superalloy," Surface and Coatings Technology, vol. 192, no. 1, pp. 27-38, 2005.

[23] T. S. Sidhu, R. D. Agrawal, and S. Prakash, "Hot corrosion of some superalloys and role of high-velocity oxy-fuel spray coatings: a review," Surface and Coatings Technology, vol. 198, no. 1-3, pp. 441-446, 2005.

[24] Y. H. Yoo, D. P. Le, J. G. Kim, S. K. Kim, and P. V. Vinh, “Corrosion behavior of TiN, TiAlN, TiAlSiN thin films deposited on tool steel in the 3.5 wt.\% NaCl solution," Thin Solid Films, vol. 516, no. 11, pp. 3544-3548, 2008.

[25] C. V. Falub, A. Karimi, M. Ante, and W. Kalss, "Interdependence between stress and texture in arc evaporated Ti-Al-N thin films," Surface and Coatings Technology, vol. 201, no. 12, pp. 5891-5898, 2007.

[26] B. Y. Man, L. Guzman, A. Miotello, and M. Adami, "Microstructure, oxidation and H2-permeation resistance of TiAlN films deposited by DC magnetron sputtering technique," Surface and Coatings Technology, vol. 180-181, pp. 9-14, 2004. 
[27] A. E. Reiter, V. H. Derflinger, B. Hanselmann, T. Bachmann, and $\mathrm{B}$. Sartory, "Investigation of the properties of $\mathrm{Al}_{1-x} \mathrm{Cr}_{x} \mathrm{~N}$ coatings prepared by cathodic arc evaporation," Surface and Coatings Technology, vol. 200, no. 7, pp. 2114-2122, 2005.

[28] J. L. Endrino, G. S. Fox-Rabinovich, and C. Gey, "Hard AlTiN, AlCrN PVD coatings for machining of austenitic stainless steel," Surface and Coatings Technology, vol. 200, no. 24, pp. 68406845, 2006.

[29] B. D. Cullity, Elements of X-Ray Diffraction, Addison-Wesley, Reading, Mass, USA, 1970.

[30] S. Adachi and K. Nakata, "Improvement of adhesive strength of Ti-Al plasma-sprayed coatings," Surface and Coatings Technology, vol. 201, pp. 5617-5620, 2007.

[31] R. C. Tucker Jr., "Advanced thermal spray deposition techniques," in Handbook of Deposition Technologies For Films and Coatings, R. F. Bunshah, Ed., chapter 11, Noyes Publications, Park Ridge, NJ, USA; William Andrew Publishing, New York, NY, USA, 1994.

[32] P. Vuoristo, K. Niemi, A. Makela, and T. Mantyla, "Abrasion and erosion wear resistance of $\mathrm{Cr}_{3} \mathrm{C}_{2}-\mathrm{NiCr}$ coatings prepared by plasma, detonation and high-velocity oxyfuel spraying," in Proceedings of the 7th National Thermal Spray Conference, pp. 121-126, Boston, Mass, USA, 1994.

[33] H. Chen and I. M. Hutchings, "Abrasive wear resistance of plasma-sprayed tungsten carbide-cobalt coatings," Surface and Coatings Technology, vol. 107, no. 2-3, pp. 106-114, 1998.

[34] R. Westergård, L. C. Erickson, N. Axén, H. M. Hawthorne, and S. Hogmark, "The erosion and abrasion characteristics of alumina coatings plasma sprayed under different spraying conditions," Tribology International, vol. 31, no. 5, pp. 271-279, 1998.

[35] V. Higuera Hidalgo, F. J. Belzunce Varela, and E. Fernández Rico, "Erosion wear and mechanical properties of plasmasprayed nickel- and iron-based coatings subjected to service conditions in boilers," Tribology International, vol. 30, no. 9, pp. 641-649, 1997.

[36] V. Higuera Hidalgo, J. Belzunce Varela, J. Martínez De La Calle, and A. Carriles Menéndez, "Characterisation of NiCr flame and plasma sprayed coatings for use in high temperature regions of boilers," Surface Engineering, vol. 16, no. 2, pp. 137-142, 2000.

[37] M. H. Staia, T. Valente, C. Bartuli, D. B. Lewis, and C. P. Constable, "Part I: characterization of $\mathrm{Cr}_{3} \mathrm{C}_{2}-25 \% \mathrm{NiCr}$ reactive plasma sprayed coatings produced at different pressures," Surface and Coatings Technology, vol. 146-147, pp. 553-562, 2001.

[38] S. T. Bluni and A. R. Marder, "Effects of thermal spray coating composition and microstructure on coating response and substrate protection at high temperatures," Corrosion, vol. 52, no. 3 , pp. 213-218, 1996.

[39] S. Deshpande, S. Sampath, and H. Zhang, "Mechanisms of oxidation and its role in microstructural evolution of metallic thermal spray coatings: case study for Ni-Al," Surface and Coatings Technology, vol. 200, no. 18-19, pp. 5395-5406, 2006.

[40] H. Herman, Plasma Sprayed Coatings, Scientific American, 1988.

[41] K. Korpiola and P. Vuoristo, "Effect of HVOF gas velocity and fuel to oxygen ratio on the wear properties of tungsten carbide coating," in Thermal Spray: Practical Solutions For Engineering Problems, C. C. Bernt, Ed., Cincinnati, Ohio, USA, 1996.

[42] J. E. Nerz, B. A. Kushner, and A. J. Rotolico, "Microstructural evaluation of tungsten carbide-cobalt coatings," Journal of Thermal Spray Technology, vol. 1, no. 2, pp. 147-152, 1992.
[43] B. Wang, R. F. Huang, G. H. Song et al., "Interdiffusion behavior of Ni-Cr-Al-Y coatings deposited by arc-ion plating," Oxidation of Metals, vol. 56, no. 1-2, pp. 1-13, 2001. 

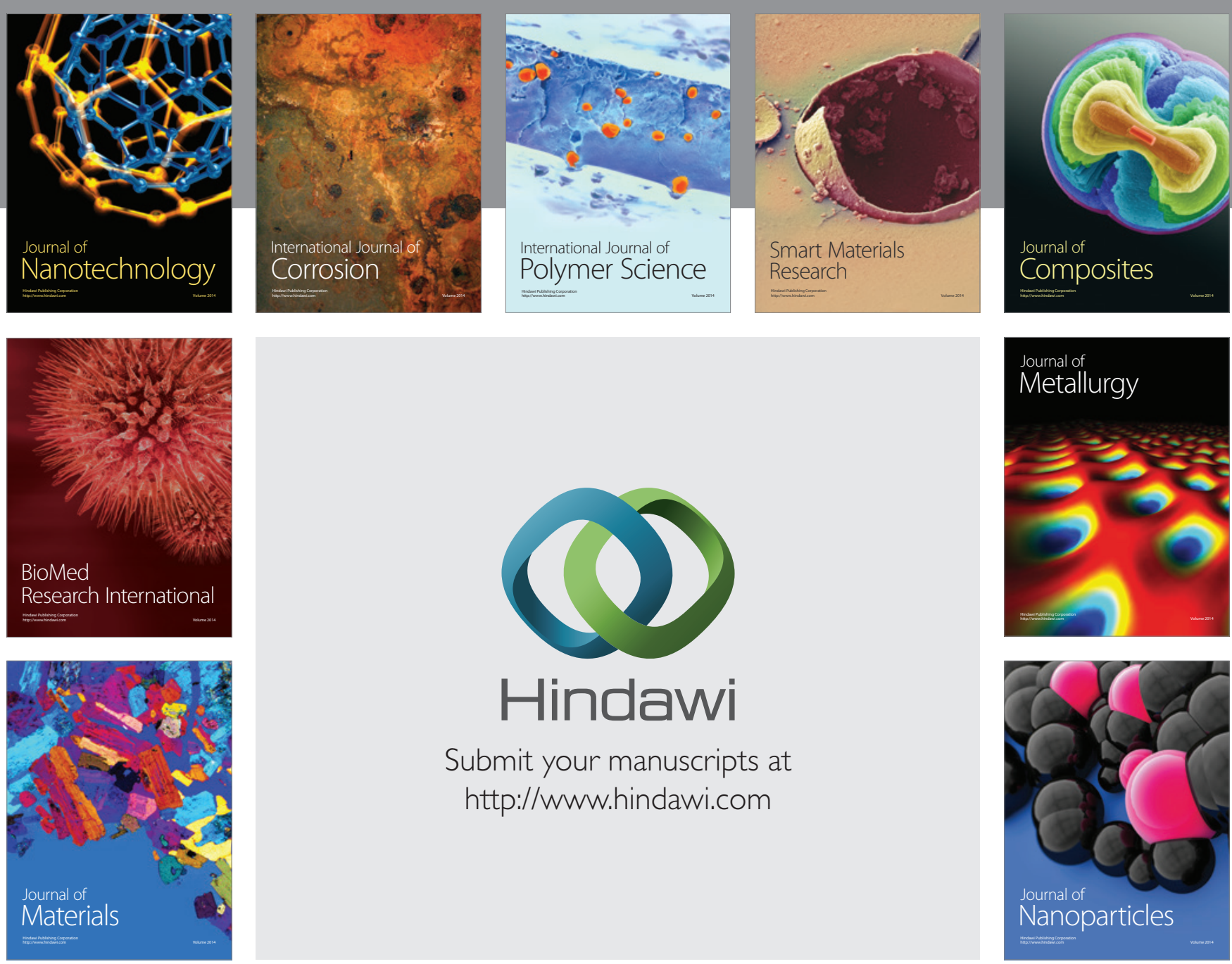

Submit your manuscripts at http://www.hindawi.com
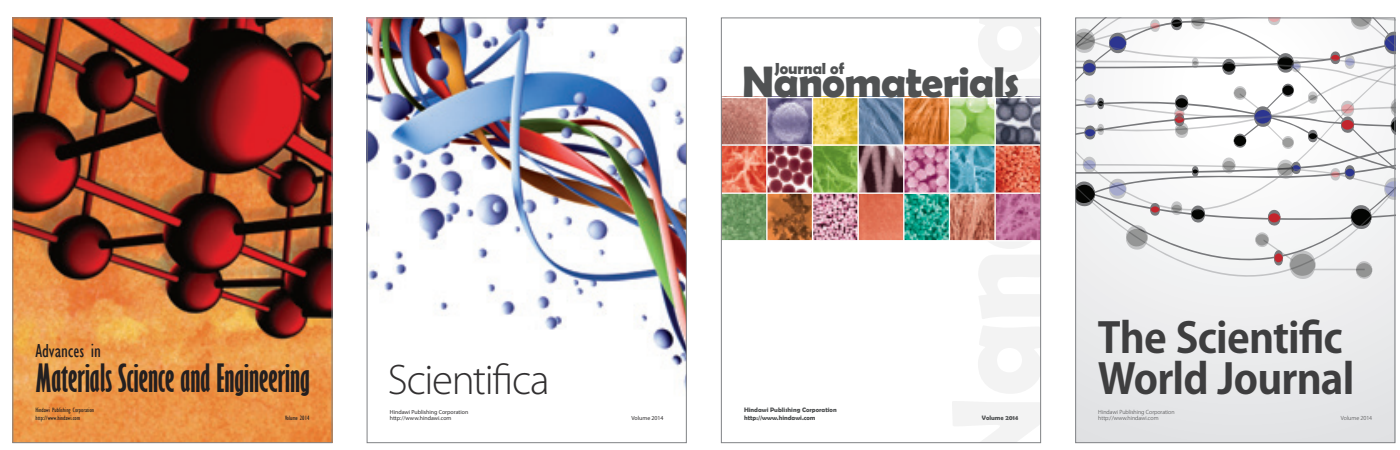

\section{The Scientific World Journal}
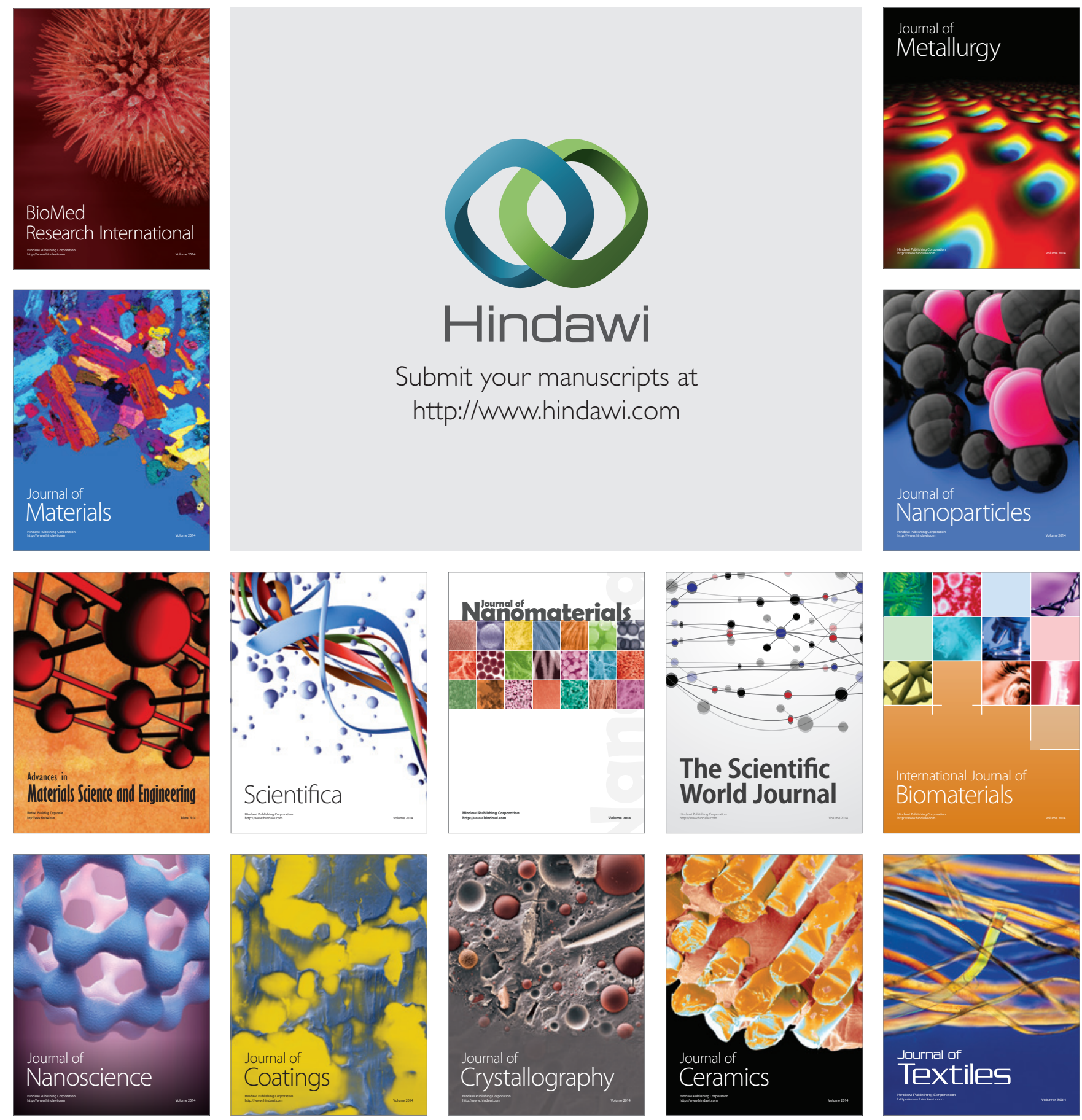